\title{
Significant improvement of cloud representation in the global climate model MRI-ESM2
}

\author{
Hideaki Kawai, Seiji Yukimoto, Tsuyoshi Koshiro, Naga Oshima, Taichu Tanaka, Hiromasa Yoshimura, and \\ Ryoji Nagasawa
}

Meteorological Research Institute, Japan Meteorological Agency, Tsukuba, 305-0052, Japan

Correspondence: Hideaki Kawai (h-kawai@ mri-jma.go.jp)

Received: 28 January 2019 - Discussion started: 28 March 2019

Revised: 6 June 2019 - Accepted: 13 June 2019 - Published: 12 July 2019

\begin{abstract}
The development of the climate model MRIESM2 (Meteorological Research Institute Earth System Model version 2), which is planned for use in the sixth phase of the Coupled Model Intercomparison Project (CMIP6) simulations, involved significant improvements to the representation of clouds from the previous version MRI-CGCM3 (Meteorological Research Institute Coupled Global Climate Model version 3), which was used in the CMIP5 simulations. In particular, the serious lack of reflection of solar radiation over the Southern Ocean in MRI-CGCM3 was drastically improved in MRI-ESM2. The score of the spatial pattern of radiative fluxes at the top of the atmosphere for MRI-ESM2 is better than for any CMIP5 model. In this paper, we set out comprehensively the various modifications related to clouds that contribute to the improved cloud representation and the main impacts on the climate of each modification. The modifications cover various schemes and processes including the cloud scheme, turbulence scheme, cloud microphysics processes, interaction between cloud and convection schemes, resolution issues, cloud radiation processes, interaction with the aerosol model, and numerics. In addition, the new stratocumulus parameterization, which contributes considerably to increased low-cloud cover and reduced radiation bias over the Southern Ocean, and the improved cloud ice fall scheme, which alleviates the time-step dependency of cloud ice content, are described in detail.
\end{abstract}

\section{Introduction}

The representation of clouds is crucially important for climate models because errors in simulated radiative fluxes are caused mainly by poor representation of cloud rather than by errors in the clear-sky radiation calculation. Consequently, biases in clouds are the major factor for biases in the radiation budget and sea surface temperature (SST) that essentially determine the basic performance of climate models. In addition, it is widely recognized that a large part of the uncertainty in projected increases in surface temperature in global warming simulations by climate models arises from large uncertainties in cloud feedback (e.g., Soden and Held, 2006; Soden et al., 2008). To obtain reliable cloud feedback in the climate models used for the projection, clouds must be represented realistically, at least in their climatology. Therefore, cloud schemes and their related processes are the most important atmospheric physical processes to be considered and carefully examined in the development of climate models.

When a climate model undergoes a major upgrade with a new version name, many minor modifications are often included rather than the introduction of a completely new sophisticated scheme. However, details of such minor modifications including the technical information and the tuning of physics schemes related to clouds are generally not provided, although such information is very useful and includes much scientific and technical value. Mauritsen et al. (2012) is one example of a publication that provides practical and honest information for tuning of a climate model.

We participated in the fifth phase of the Coupled Model Intercomparison Project (CMIP5) (Taylor et al., 2012) and the Cloud Feedback Model Intercomparison Project Phase 2 (CFMIP-2) (Bony et al., 2011) using our global cli- 
mate model, MRI-CGCM3 (Meteorological Research Institute Coupled Global Climate Model version 3; Yukimoto et al., 2012, 2011). However, its representation of clouds was unsatisfactory. In the updated version of our climate model, MRI-ESM2 (Meteorological Research Institute Earth System Model version 2; Yukimoto et al., 2019), which is planned for use in CMIP6 (Eyring et al., 2016) and CFMIP-3 (Webb et al., 2017) simulations, the representation of clouds is significantly improved. The score of the spatial pattern of radiative fluxes for MRI-CGCM3 was worse than the average of the 48 CMIP5 models, but the score for MRI-ESM2 is better than any of them. The improvement is particularly pronounced over the Southern Ocean. Trenberth and Fasullo (2010) showed that a significant lack of clouds over the Southern Ocean is a serious problem in most climate models and causes huge biases in shortwave radiative flux there. Although MRI-CGCM3 had this problem with biases that were worse than the average CMIP5 model, the biases are dramatically reduced in the new model, MRI-ESM2.

The problems related to clouds in MRI-CGCM3 cover a broad range of issues. For instance, low-cloud cover over the midlatitude and subtropical oceans is insufficient, the ratio of supercooled liquid water to cloud (liquid and ice) water is too small, the number concentration of cloud droplets of the Southern Ocean clouds is inadequate, the reflection of solar radiation over the tropics is overestimated, vertical structures of low-cloud transition are unrealistic, there are several coding bugs and ice water content shows strong time-step dependency. To solve these problems and give a better physical basis to the processes, many modifications were implemented in MRI-ESM2. The model update includes

i. the introduction of a new stratocumulus parameterization,

ii. a modified treatment of the Wegener-BergeronFindeisen (WBF) process,

iii. a modified treatment of interaction between stratocumulus and shallow convection,

iv. an increase in the vertical resolution,

v. the introduction of a new cloud overlap scheme,

vi. increased horizontal resolution for the radiation calculation,

vii. various bug fixes,

viii. updated aerosol size distributions,

ix. an improved cloud ice fall scheme.

Item (i) is related to the cloud and turbulence schemes, (ii) to cloud microphysics process, (iii) to interaction between the cloud and convection schemes, (iv) and (vi) to resolution issues, (v) to cloud radiation process, (viii) to the aerosol properties, and (ix) to numerics. Improvements and modifications in this wide range of processes contribute to the improved cloud representation in MRI-ESM2. It is worth describing the main effect of each modification separately with the background of the modification, and such information is very useful for model developers. We would like to emphasize again that the improvement of climate model performance due to updates is ordinarily contributed by the cumulative effect of a lot of modifications, some of which may seem to be minor, rather than by the introduction of a new sophisticated scheme. In this paper, the impacts of each modification are examined by comparing the result of a control AMIP (Atmospheric Model Intercomparison Project) simulation using the new model MRI-ESM2 and results of AMIP experiments in which each updated process is separately turned off.

In addition, the new stratocumulus parameterization, which contributes considerably to increased low-cloud cover and reduced radiation bias over the Southern Ocean, includes scientifically new concepts, and the improved cloud ice fall scheme, which alleviates the time-step dependency of cloud ice content, includes technically important issues. Therefore, these two items are described in detail in the later section.

\section{Models and experiments}

\subsection{Models}

The cloud scheme in MRI-CGCM3 (Yukimoto et al., 2012, 2011; $\mathrm{T}_{\mathrm{L}} 159 \mathrm{~L} 48$ in the standard configuration) is a twomoment cloud scheme developed and modified from the Tiedtke cloud scheme (Tiedtke, 1993; Jakob, 2000). Cloud fraction, cloud liquid water and cloud ice water contents (LWCs and IWCs), number concentrations of cloud droplets, and ice crystals are prognostic variables. The source and sink terms of cloud fraction, LWC and IWC are calculated basically following Tiedtke (1993): the source terms include the formation of stratiform cloud due to upward motion and temperature decrease and detrainment from convection, and sink terms include evaporation. For the temperature range from -38 to $0^{\circ} \mathrm{C}$, deposition nucleation is calculated based on Meyers et al. (1992), and depositional growth and evaporation for cloud ice are calculated following Rutledge and Hobbs (1983). As processes for freezing of cloud droplets to ice crystals, immersion, condensation (Bigg, 1953; Murakami, 1990; Levkov et al., 1992; Lohmann, 2002) and contact freezing (Lohmann and Diehl, 2006; Cotton et al., 1986) are calculated. Conversion of LWC to rain is calculated based on Manton and Cotton (1977) and Rotstayn (2000). Melting of cloud ice and snow occurs just below an altitude where the atmospheric temperature is $273.15 \mathrm{~K}$. In MRIESM2 (Yukimoto et al., 2019; $\mathrm{T}_{\mathrm{L}} 159 \mathrm{~L} 80$ in the standard configuration), all these processes are essentially the same as in MRI-CGCM3. The treatments of stratocumulus, the Bergeron-Findeisen effect, cloud ice fall and conversion of 
IWC to snow are discussed later in detail because they are modified from MRI-CGCM3 to MRI-ESM2.

Aerosols are calculated by the Model of Aerosol Species in the Global Atmosphere mark-2 revision 4-climate (MASINGAR mk-2r4c) (Yukimoto et al., 2011, 2019; Tanaka et al., 2003), which is coupled to MRI-ESM2. Five species of aerosols are utilized in the cloud and radiation schemes: sulfate, black carbon, organic matter, sea salt (two size modes) and mineral dust (six size bins). The activation of aerosols into cloud droplets is calculated based on AbdulRazzak et al. (1998), Abdul-Razzak and Ghan (2000), and Takemura et al. (2005). The ice nucleation for cirrus clouds is calculated using a parameterization of Kärcher et al. (2006), including homogeneous nucleation (Kärcher and Lohmann, 2002) and heterogeneous nucleation (Kärcher and Lohmann, 2003).

\subsection{Basic performance}

First, we briefly show improvements from MRI-CGCM3 to MRI-ESM2 in the basic performance of the simulations. Figure 1 shows the total cloud cover and its bias in the present-day climate from the historical simulations using MRI-CGCM3 and MRI-ESM2. Observational data for total cloud cover (Pincus et al., 2012; Zhang et al., 2012) that are derived from the International Satellite Cloud Climatology Project (ISCCP; Rossow and Schiffer, 1999) D1 data and radiative flux observational data from the Clouds and Earth's Radiant Energy Systems (CERES) Energy Balanced and Filled (EBAF; Loeb et al., 2009) product are used as observational climatologies. It is clear that total cloud cover simulated by MRI-CGCM3 is much less than the observations, especially over the Southern Ocean and subtropical oceans off the west coast of the continents. However, total cloud cover is substantially increased in the simulation using MRI-ESM2 over these areas and the bias is reduced significantly. As a result, a large negative bias in the upward shortwave radiative flux at the top of the atmosphere (TOA) found in MRI-CGCM3 is reduced substantially in the simulation using MRI-ESM2. In addition, a positive bias in the tropics is also reduced.

Figure 2 shows the Taylor diagrams (Taylor, 2001) for upward shortwave, longwave and net radiative fluxes from the 48 CMIP5 models. The scores of spatial patterns of shortwave, longwave and net radiative fluxes for MRI-CGCM3 are near or worse than the average among the 48 CMIP5 models, but the scores for MRI-ESM2 are better than any of the models. The scores for MRI-ESM2 are even almost comparable to the scores of the ensemble mean of CMIP5 models. Although the uncertainty in the observational data for cloud radiative effect is larger than that of radiative fluxes at the top of the atmosphere, the scores of cloud radiative effect for shortwave, longwave, and net radiation show similar characteristics to the corresponding scores for TOA radiative fluxes (Fig. S1 in the Supplement). This implies that im- provement of TOA radiative fluxes in MRI-ESM2 can be attributed to improvement of cloud representation in the model.

\subsection{Experiments}

The purpose of this paper is to identify the effect of each modification applied to the model under controlled conditions in order to understand the significant improvement of the radiative flux in the new model. Therefore, we chose AMIP simulations to avoid being influenced by changes in SST. A series of experiments with the new model MRIESM2 is performed, with each modification summarized in Sect. 1 in turn set to the old (MRI-CGCM3) treatment. A list of sensitivity experiments performed in the present study using MRI-ESM2 is given in Table 1. We ran the model from 2000 to 2010 and used the data for 10 years from 2001 to 2010 for analysis.

\section{Updates and their impacts}

In this section, the updates from various aspects are explained with their backgrounds. The main impact of each update is shown and discussed based on the comparison between the results of the updated new model and the experiments in which each modification in turn is turned back to the old treatment.

\subsection{New stratocumulus parameterization}

The representation of low clouds including stratocumulus in climate models has been one of the most bothersome problems for many years (e.g., Duynkerke and Teixeira, 2001; Siebesma et al., 2004), and low clouds are poorly reproduced even in the state-of-the-art climate models (e.g., Nam et al., 2012; Su et al., 2013; Caldwell et al., 2013; Koshiro et al., 2018). As a result, solar reflectance by clouds has significant negative biases over areas frequently covered by stratocumulus (e.g., Trenberth and Fasullo, 2010; Li et al., 2013). A new stratocumulus scheme that utilizes a stability index that takes into account the effect of cloud top entrainment (Kawai et al., 2017) was introduced instead of the old stratocumulus scheme (Kawai and Inoue, 2006). A detailed description and physical interpretation are given in Sect. 4. Figure 3 shows that low-cloud cover increases significantly in the subtropical oceans off the west coast of the continents and over the Southern Ocean, which is a significant result of upgrading the stratocumulus scheme. Low-cloud cover is increased by more than $20 \%$ over the oceans off California, Peru, Namibia and the west coast of Australia and by more than $10 \%$ over the Southern Ocean. As a result, upward shortwave radiative flux (reflection of solar insolation) also increases, and this impact contributes to reducing the large bias in shortwave radiative flux over these regions. 

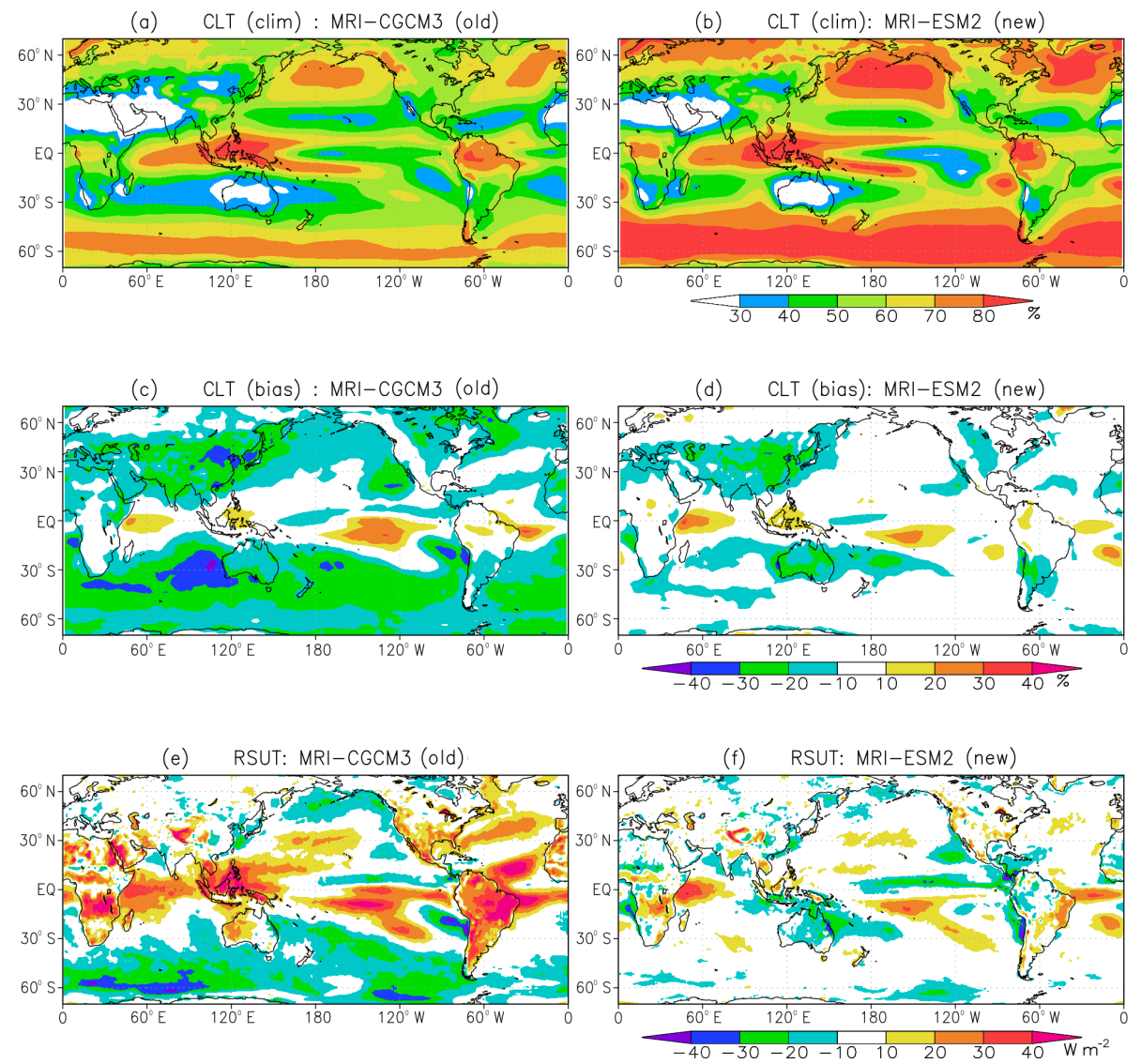

Figure 1. (a, b) Climatologies of total cloud cover $(\%),(\mathbf{c}, \mathbf{d})$ biases of total cloud cover (\%) with respect to ISCCP observations and (e, f) biases of upward shortwave radiative flux $\left(\mathrm{W} \mathrm{m}^{-2}\right)$ at the top of the atmosphere with respect to CERES-EBAF simulated by (a, c, e) MRICGCM3 and (b, d, f) MRI-ESM2. The climatologies cover the period 1986-2005 for model simulations and ISCCP observational data and 2001-2010 for CERES-EBAF data.
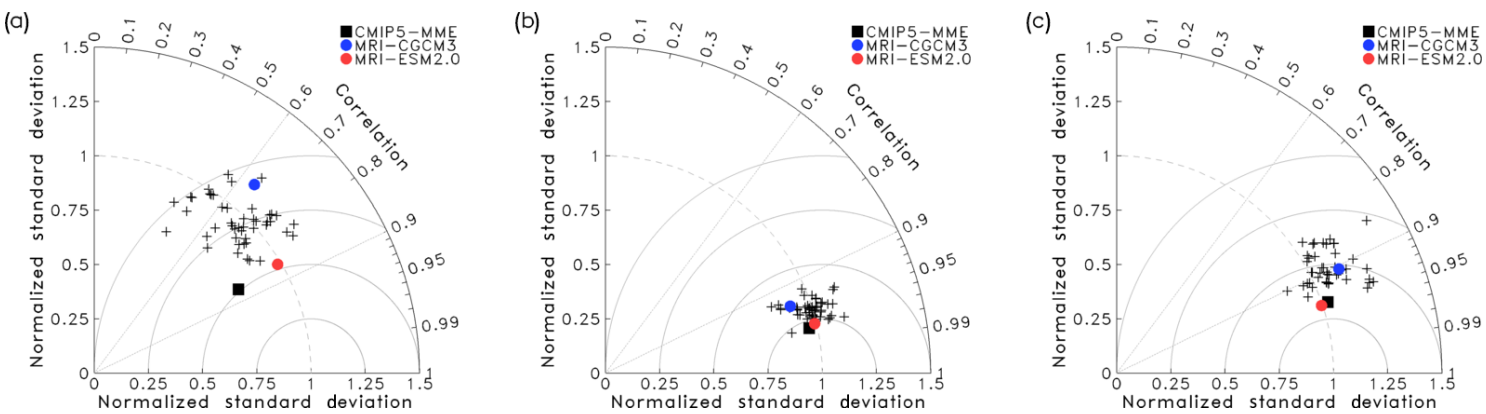

Figure 2. Taylor diagrams for upward (a) shortwave, (b) longwave and (c) net radiative fluxes at the top of the atmosphere for MRI-CGCM3 (blue dot), MRI-ESM2 (red dot), the CMIP5 multi-model mean (black square) and individual CMIP5 models (crosses). CERES-EBAF data are used as observations.

\subsection{Treatment of the WBF effect}

In recent years, several studies (e.g., McCoy et al., 2015; Cesana and Chepfer, 2013) revealed that ratios of supercooled liquid water with respect to cloud (liquid + ice) water in climate models are much lower than those in the CloudAerosol Lidar and Infrared Pathfinder Satellite Observations
(CALIPSO; Winker et al., 2009) data (e.g., Hu et al., 2010; Cesana and Chepfer, 2013). Some studies pointed out that the lack of supercooled liquid water in climate models is the source of insufficient solar reflectance of clouds over the Southern Ocean (e.g., Bodas-Salcedo et al., 2016; Kay et al., 2016). Liquid clouds are optically thicker than ice clouds if the cloud (liquid + ice) water content is the same because 
Table 1. List of sensitivity experiments performed in the present study using MRI-ESM2 to identify the effect of each modification. The second column shows the section in which each modification is discussed.

\begin{tabular}{lc}
\hline Experiments & Section \\
\hline Control (time step = 3600, 1800 (default), 900 and $300 \mathrm{~s})$ & 3.1 \\
With an old version of stratocumulus scheme & 3.2 \\
With an old treatment of the WBF effect & 3.3 \\
Shallow convection can be active even under stratocumulus conditions & 3.4 \\
Shallow convection can be active even under stratocumulus conditions using L48 & 3.5 \\
With an old version of cloud overlap scheme & 3.6 \\
Radiation calculation for every two latitudinal grids & 3.6 \\
One-hourly longwave radiation calculation & 3.8 \\
Using original (not doubled) number concentration of sea salt CCN & 3.9 \\
With an old version of ice fall scheme (time step = 3600, 1800, 900 and 300 s) & \\
\hline
\end{tabular}
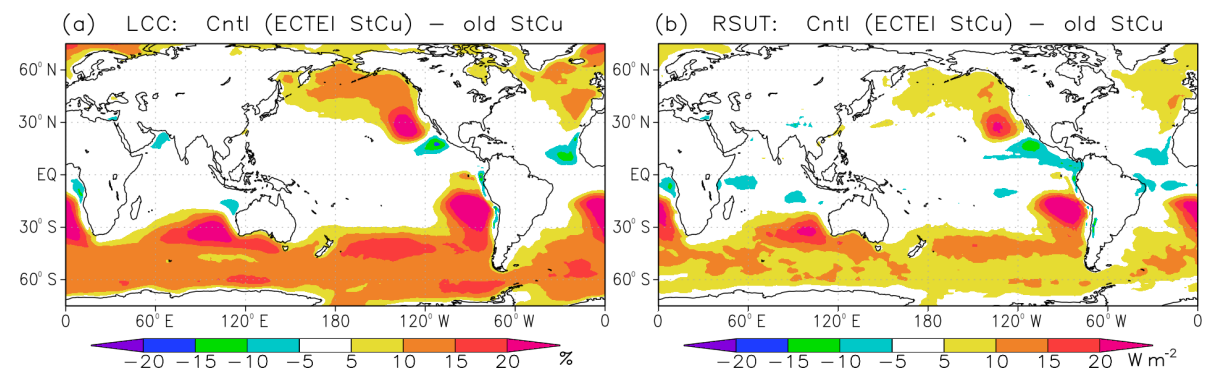

Figure 3. Impacts of the new stratocumulus scheme on (a) low-cloud cover (\%) and (b) TOA upward shortwave radiative flux (W $\mathrm{m}^{-2}$ ). The plots show results for the control model (with the new stratocumulus scheme) minus those for an experiment with an old version of the stratocumulus scheme.

the size of cloud droplets is much smaller than that of ice crystals and this corresponds to larger number concentration for cloud droplets.

The WBF process is a deposition growth process of ice crystals at the expense of cloud droplets due to ice saturation being lower than liquid water saturation. The WBF effect was treated in a way similar to Lohmann et al. (2007) in MRI-CGCM3. When IWC is greater than a threshold of $0.5 \mathrm{mg} \mathrm{kg}^{-1}$, all supercooled water in the grid box is forced to evaporate within the time step and all source terms for LWC are set to zero. However, this treatment caused excessive evaporation of supercooled water. In MRI-ESM2, when IWC exceeds the threshold, only the part of LWC that corresponds to the depositional growth of ice crystals is evaporated within the time step. In addition, the source terms of LWC are not ignored but calculated in a proper fashion. However, there is an arbitrariness about how these source terms are divided into the source terms of LWC and IWC. The first reason for the arbitrariness is that the time step of our climate models is too long $(30 \mathrm{~min})$ to resolve cloud microphysics and a part of the generated liquid water can change to ice crystals within this time step, especially when IWC exceeds the threshold. The second reason is that the liquid water and ice water are assumed to be well mixed in the model grid box if they coexist, as in most global climate models. However, there should be mixed-phase parts, ice-only parts and liquid-only parts in a volume corresponding to the model grid box size (Tan and Storelvmo, 2016). Therefore, it is difficult to determine the LWC-IWC partitioning of the source terms theoretically. We decided to use a ratio derived by $\mathrm{Hu}$ et al. (2010) based on satellite observations to determine the ratio of the source terms into LWC and IWC only when the WBF effect occurs, that is, when IWC is greater than the threshold. This is an empirical and simple method, but this treatment can supplement the defects of the modeled microphysics due to the uncertainty and complexity by utilizing observational data.

Figure 4 shows the ratio of supercooled liquid water in clouds as a function of temperature in the simulations using new and old treatments of the WBF effect. It is clear from the figure that the ratio of supercooled liquid water is significantly increased in the new treatment and close to the satellite observations of $\mathrm{Hu}$ et al. (2010); the ratio at $255 \mathrm{~K}$ is increased from $52 \%$ to $84 \%$ for the mass-weighted ratio and from $18 \%$ to $78 \%$ for the frequency ratio. Both mass-weighted ratio and frequency ratio, which should correspond to the ratio derived from satellite observations, using the new treatment, are close to the satellite observations. In MRI-ESM2, IWC production from the source terms of LWC based on partitioning using a function of $\mathrm{Hu}$ et al. (2010) is dominant, and the contributions from a depositional growth and other freezing processes are considerably small. Figure 5 


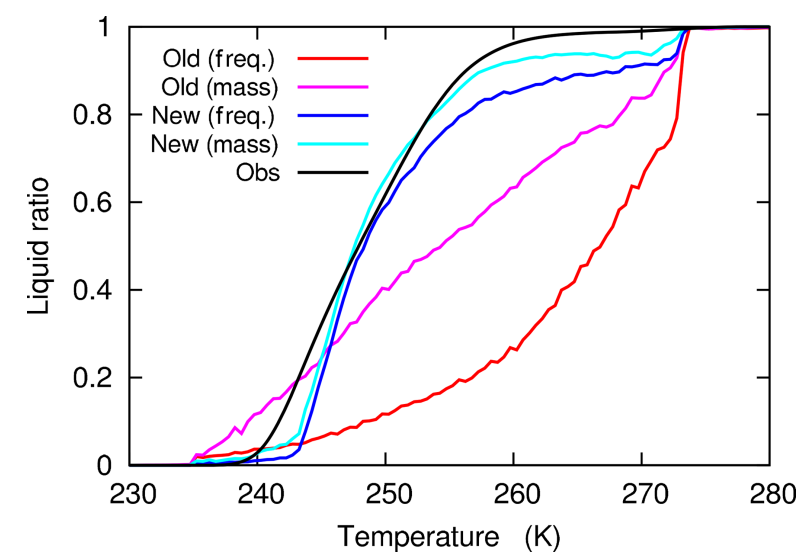

Figure 4. Ratio of supercooled liquid water to total cloud water as a function of temperature. The plot is obtained from snapshot of global data for $10 \mathrm{~d}$ in July 2001 using the old (red and pink lines) and new (blue and light blue lines) treatments of the WBF effect. The ratios are calculated using two methods: mass-weighted ratio (pink and light blue lines), in which liquid and ice masses are averaged over temperature bins first and the liquid water ratio is calculated from the averaged masses, and frequency ratio (red and blue lines), in which the snapshot ratio of liquid water is weighted by snapshot cloud fraction and averaged over temperature bins. An observational curve from $\mathrm{Hu}$ et al. (2010) that corresponds to a frequency ratio is also shown (black line).

shows the impact of the new treatment of the WBF effect on TOA upward shortwave radiative flux. The reflection of solar insolation is significantly increased over the Southern Ocean using the new treatment (Fig. 5), and consequently, this new treatment contributes considerably to the reduction in shortwave radiation bias over the area shown in Fig. 1. The increase in the ratio of supercooled liquid water in MRI-ESM2 plausibly contributes to the higher climate sensitivity in the model than in MRI-CGCM3 because an increased ratio of supercooled liquid water weakens the cloud-phase feedback that negatively contributes to cloud feedback (Tsushima et al., 2006; McCoy et al., 2015; Bodas-Salcedo et al., 2016; Kay et al., 2016; Tan et al., 2016; Frey and Kay, 2018).

However, since the new treatment of the WBF effect is still rather simple, it cannot represent observed layered structures with a thin supercooled water layer at the top of cloud layers and the ice layer below (Forbes and Ahlgrimm, 2014; Forbes et al., 2016). In addition, it is possible that the curve of $\mathrm{Hu}$ et al. (2010) overestimates the ratio of supercooled liquid water (Cesana and Chepfer, 2013; Cesana et al., 2016). It should also be noted that empirical relationships including the ratio curve of Hu et al. (2010) may not hold completely in a future climate because a large number of meteorological factors contribute to form such relationships and they may change in a systematic way. Therefore, more sophisticated treatments need to be developed in the future.

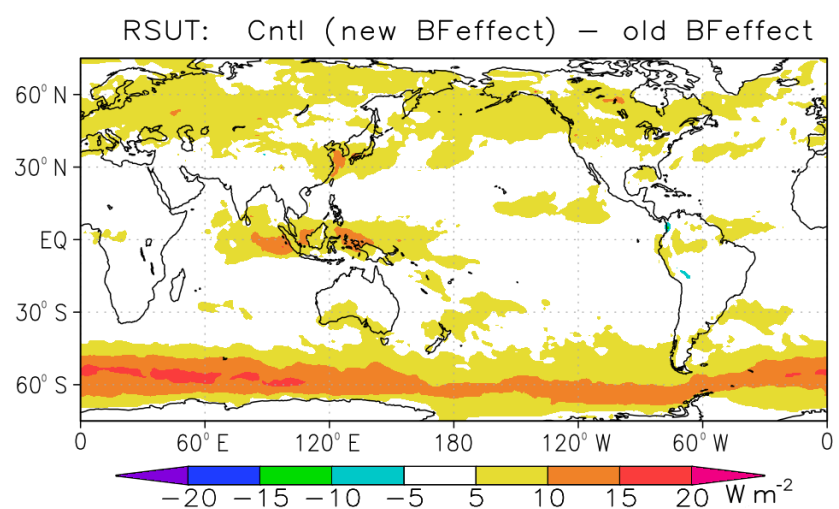

Figure 5. Impact of the new treatment of the WBF effect on TOA upward shortwave radiative flux $\left(\mathrm{W} \mathrm{m}^{-2}\right)$. The plot shows the results for the control model (with the new treatment) minus those for an experiment with an old version of the treatment.

\subsection{Interaction between stratocumulus and shallow convection}

It is well-known that the altitude of the low-level cloud layer gradually increases westward in subtropical stratocumulus regions, including off Peru, in association with the transition from stratocumulus to cumulus (Bretherton et al., 2010; Rahn and Garreaud, 2010; Abel et al., 2010; Kawai et al., 2015a). However, the vertical structures of the transition were unrealistically discontinuous in the old model as seen in Fig. 6b. This discontinuity was caused by an unrealistically formed temperature inversion just above the stratocumuluslike cloud layer due to excessive adiabatic heating by the convection scheme that activates shallow convection in those regions. Therefore, in the new version, the occurrence of shallow convection is prevented over the area where the conditions for stratocumulus occurrence (see Sect. 4.1 in more detail) are met. As a result, the vertical structures of lowlevel clouds are significantly improved, as seen in Fig. 6a. Such a switch for shallow convection is sometimes used in atmospheric models, although it is a simple and practical method. For example, a threshold of estimated inversion strength (EIS; Wood and Bretherton, 2006) is used to determine the activation of shallow convection in version CY43r3 of the European Centre for Medium-Range Weather Forecasts (ECMWF) Integrated Forecast System (IFS) (ECMWF, 2017).

\subsection{Vertical resolution}

The thickness of observed stratocumulus is typically 200 $300 \mathrm{~m}$ (Wood, 2012), but can be as thin as $50 \mathrm{~m}$ during the daytime, especially in the Californian stratocumulus region (Betts, 1990; Duynkerke and Teixeira, 2001). The model vertical resolution was increased from L48 (48 vertical levels) in MRI-CGCM3 to L80 in MRI-ESM2 (Yukimoto et al., 2019), and the number of vertical layers in the atmospheric bound- 

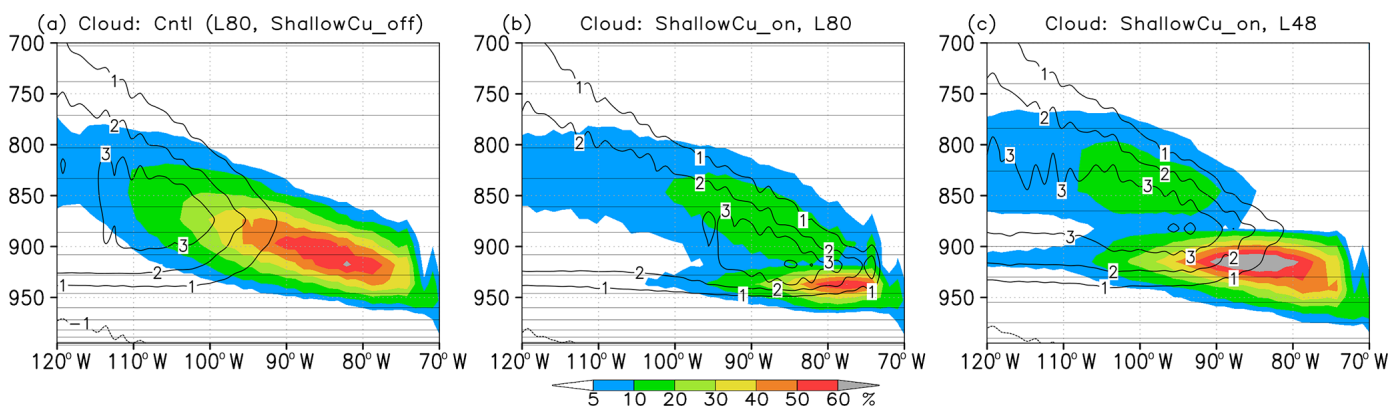

Figure 6. Cross sections of cloud fraction (color, \%) along $20^{\circ} \mathrm{S}$ for January. (a) The control model (L80, a treatment of shallow convection suppressed under stratocumulus conditions), (b) the same as (a) but where shallow convection can be active even under stratocumulus conditions, and (c) the same as (b) except for vertical resolution L48. Horizontal straight lines show the vertical model layers, and contours show the heating rate of the convection scheme $\left(\mathrm{Kd}^{-1}\right)$.

ary layer was nearly doubled (from 5 to 10 layers below $900 \mathrm{hPa})$. As seen in Fig. 6c, the low-cloud layer can be geometrically too thick in the model with resolution L48, which can cause too high an albedo because the vertical layer thickness is about $300 \mathrm{~m}$ at the level of $900 \mathrm{hPa}$ and this is the minimum thickness of clouds that can be represented in the model. The sensitivity of the represented stratocumulus to model vertical resolution has been widely reported (Teixeira, 1999; Bushell and Martin, 1999; Wang et al., 2004; Wilson et al., 2008; Neubauer et al., 2014; Guo et al., 2015). Although several methods that compensate for insufficient vertical resolution have been developed, including the use of vertical sublevels (Wilson et al., 2007) and the introduction of areal cloud fraction, which is different from volume cloud fraction (Brooks et al., 2005), we decided for the moment not to introduce those methods for simplicity and consistency in the model physics.

\subsection{Cloud overlap}

In the longwave radiation scheme, maximum-random overlap (Geleyn and Hollingsworth, 1979) is adopted as a cloud overlap assumption. In contrast, in the shortwave radiation scheme, total cloud cover in a column (the cloudy area) is first calculated based on maximum-random overlap, and second, random overlap is adopted indirectly to calculate multiple scattering in the cloudy area in MRI-CGCM3 (Yukimoto et al., 2011, 2012). However, the inadequate treatment of the cloud overlap assumption in the shortwave radiation scheme causes overestimation of the reflection of incident solar radiative flux, especially for tower-shaped cumulus clouds with optically thin high-level clouds (e.g., anvil) (Nagasawa, 2012). In MRI-ESM2, because a practical independent column approximation (PICA; Nagasawa, 2012) based on Collins (2001) was implemented, the maximumrandom overlap became available in the shortwave radiation scheme. The application of the maximum-random overlap in the shortwave radiation scheme significantly decreased the reflection of shortwave radiative flux over the tropical con- vection areas without varying total cloud cover (Fig. 7). This reduction makes a significant contribution to reduce the excessive reflection of incident shortwave radiative flux over the tropics (see Fig. 1).

\subsection{Horizontal resolution for radiation calculation}

The computational cost for radiation calculation is heavy in climate models, and this cost was reduced in MRI-CGCM3 by reducing the radiation calculation spatially and temporally. Full radiation computations were performed for every two grid boxes in the zonal direction, and shortwave and longwave radiation was calculated 1-hourly and 3-hourly, respectively. Figure 8 shows the impacts of increased horizontal resolution for the radiation calculation (calculation for every single grid) (Fig. 8a, b) and increased frequency of calculation (1-hourly calculation) for longwave radiation (Fig. 8c, d). In both cases, low-level clouds in the subtropics off the west coasts of the continents and at midlatitudes increased, increasing shortwave reflectance a little. This increase in low-cloud cover can be attributed to improved cloud-radiation interactions: cloud top longwave cooling of low clouds, which is the primary physical process to maintain low clouds (e.g., Wood, 2012), is consistently calculated at the top of existing low clouds without spatial smoothing and temporal inconsistency. Either modification is physically appropriate and improves the representation of low clouds. However, the total computational cost was increased by $5 \%$ for the spatial resolution modification and by $10 \%$ for the temporal resolution modification. Considering cost and merit comprehensively, we decided to adopt the modification only for the spatial resolution and keep the temporal treatment unchanged.

\subsection{Bug fixes}

No climate models are free from coding bugs, and they sometimes exert significant impacts on model results, although they are rarely documented in publications. MRI-CGCM3 

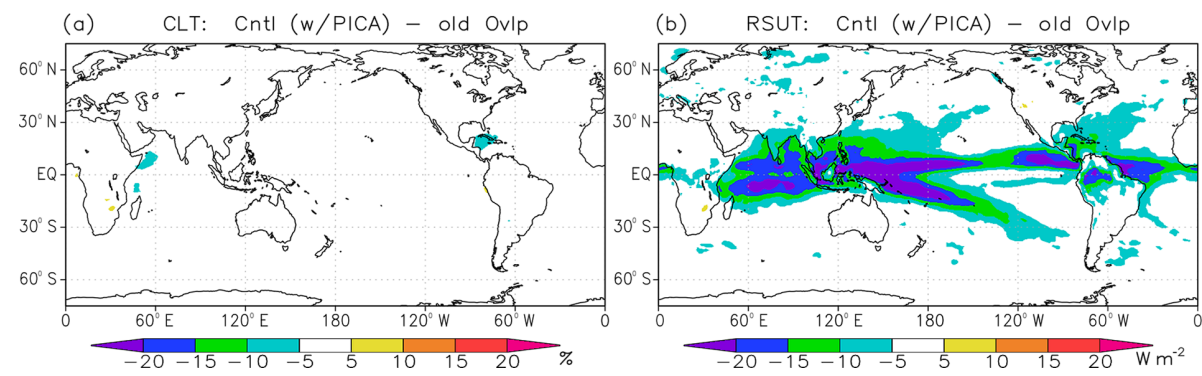

Figure 7. Impacts of new cloud overlap scheme, PICA, for shortwave radiation calculation on (a) total cloud cover (\%) and (b) TOA upward shortwave radiative flux $\left(\mathrm{W} \mathrm{m}^{-2}\right)$. The plots show results for the control model (with PICA) minus those for an experiment with an old version of the cloud overlap scheme.
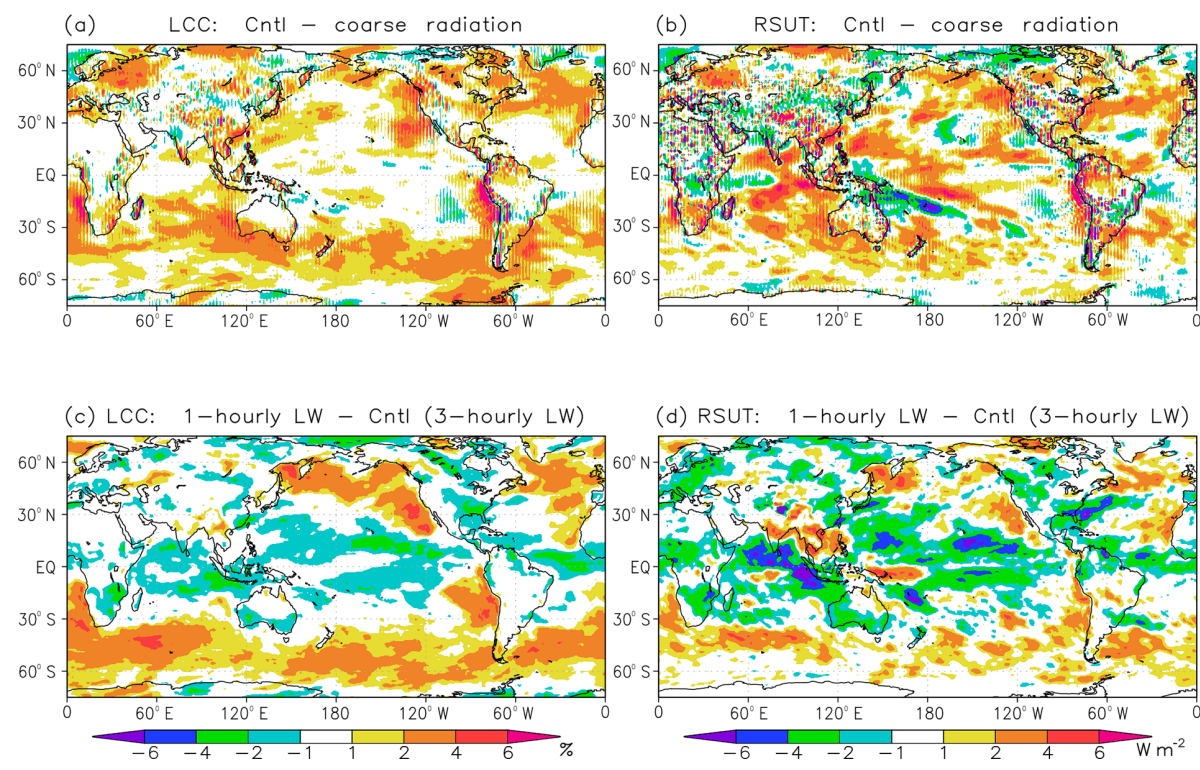

Figure 8. Impacts of $(\mathbf{a}, \mathbf{b})$ increased horizontal resolution for the radiation calculation and (c, $\mathbf{d})$ increased frequency of calculation for longwave radiation on $(\mathbf{a}, \mathbf{c})$ low-cloud cover $(\%)$ and $(\mathbf{b}, \mathbf{d})$ TOA upward shortwave radiative flux $\left(\mathrm{W} \mathrm{m}^{-2}\right)$. Panels $(\mathbf{a}, \mathbf{b})$ show results for the control model (calculation for every single grid box) minus those for an experiment with calculation for every two latitudinal grid boxes. Panels (c, d) show results for an experiment with 1-hourly longwave radiation calculation minus those for the control model (3-hourly calculation).

also had some bugs that affect the simulation results to some extent. One of them is associated with the prognostic equations for number concentrations of the cloud particles. This bug caused the problem of large number concentrations of cloud particles leading to excessive optical thickness and accompanying excessive reflection of solar radiation, particularly for stratocumulus and stratus over the subtropics and northern Pacific region (Tsushima et al., 2016). In addition, the bug caused a large decrease in the number concentration of cloud droplets and large positive cloud feedback for such clouds in warmer climate simulations (Kawai et al., 2015b). Several bugs including this serious bug were fixed in MRIESM2.

\subsection{Aerosol size distributions}

Our climate models calculate number concentrations of aerosols from the mass concentrations using the prescribed aerosol size distributions, and the number concentrations are used to calculate number concentrations of cloud particles. Therefore, an appropriate treatment of the aerosol size distributions is important to estimate the aerosol effect on clouds. Aerosol size distributions, namely the geometric mean radius and standard deviation in lognormal size distribution, were modified in MRI-ESM2 based on recent observations. For example, the increase in the geometric mean radius of organic carbon from 0.0212 (Chin et al., 2002) to $0.1 \mu \mathrm{m}$ (Seinfeld and Pandis, 2006; Liu et al., 2012) in MRI-ESM2 causes a significant decrease in the number concentration of cloud particles that originate from organic carbon. This mod- 
ification significantly decreases the response of cloud optical thickness to assumed changes in the emission of organic carbon. On the other hand, the mode radius of fine mode sea salt is decreased from 0.228 (Chin et al., 2002) to $0.13 \mu \mathrm{m}$ (Seinfeld and Pandis, 2006) and the change causes a higher number concentration of cloud droplets originating from sea salt. In addition, the number concentration of cloud condensation nuclei $(\mathrm{CCN})$ originating from fine mode sea salt is multiplied by a factor of 2.0 after the calculation from the number concentration of sea salt. This treatment is introduced because we use only two size modes (i.e., fine accumulation and coarse modes) of sea salt and the model cannot represent sea salt in the Aitken mode, although a part of the sea salt in Aitken mode can work as CCN. In fact, the number concentration of sea salt in Aitken mode is difficult to estimate from the mass concentration of aerosols because Aitken-mode sea salt contributes substantially to the number but contributes little to the mass. To represent the contribution of sea salt in Aitken mode to $\mathrm{CCN}$ in a simple way, a multiplication factor of 2.0 is applied as a provisional solution until sea salt in Aitken mode can be calculated explicitly. This factor is estimated from observational studies (e.g., Covert et al., 1996; Clarke et al., 2006). In fact, a lower limit of the number concentration of cloud droplets has been used in a significant number of state-of-the-art climate models to prevent overly small number concentrations of cloud droplets in clean air conditions (Hoose et al., 2009; Jones et al., 2001; Lohmann et al., 2007; Takemura et al., 2005). However, it is pointed out that this lower limit drastically controls the magnitude of the aerosol indirect effect, for instance, measured as the difference between present-day and preindustrial climates (Hoose et al., 2009). Therefore, the lower limit of cloud droplets is not introduced in our model. We believe that our treatment is better than introducing a lower limit of cloud droplets although it is quite simple because the treatment has a more physical basis. This treatment increases cloud droplet number concentration by more than $30 \%$ and also increases the reflection of shortwave radiation by $4 \mathrm{~W} \mathrm{~m}^{-2}$ over the Southern Ocean (Fig. 9).

\subsection{Ice sedimentation and ice conversion to snow}

The method for calculating cloud ice sedimentation in MRICGCM3 was not sophisticated, and it caused unrealistic ice sedimentation and strong time-step dependency of IWC. While IWC is a prognostic variable in MRI-CGCM3, snow is not, but it is treated as snow flux in the model. A part of IWC is diagnosed as snow and removed from the IWC at each time step and falls down to the surface within one time step. The main problem was that the ratio of snow was not proportional to the time step. As a result, a substantial amount of snow is repeatedly removed from IWC when the time step is shortened. To solve the problem, the treatment of cloud ice sedimentation and conversion of cloud ice to snow was improved based on the study of Kawai (2005). Figure 10 shows that IWC is large for a time step of $3600 \mathrm{~s}$ but monotonically decreases with shorter time steps. On the other hand, IWC is not affected by the time step in the control simulation that uses the modified scheme of ice sedimentation and ice conversion to snow. A detailed description of the modification is given in Sect. 4 because this modification contains some important insights and solutions related to the numerical issues.

\subsection{Summary of impacts on shortwave radiative flux}

Figure 11 summarizes the impacts of each modification on zonal means of low-cloud cover and TOA upward shortwave radiative flux. The new stratocumulus scheme contributes to an increase in low-cloud cover mainly over the Southern Ocean, and the suppression of shallow convection under stratocumulus conditions contributes a low-cloud cover increase over the midlatitudes in the Southern Hemisphere. Increased horizontal resolution in the radiation calculation additionally contributes to the low-cloud cover increase. The increase in reflection of solar radiation over the Southern Ocean and midlatitudes in the Southern Hemisphere is largely contributed by the new stratocumulus scheme, the new treatment of the WBF effect (especially around $60^{\circ} \mathrm{S}$ ), the doubled number concentration of sea salt $\mathrm{CCN}$, and the treatment of shallow convection suppressed under stratocumulus conditions (over latitudes lower than the areas impacted by other modifications). The new treatment of the WBF effect and doubled number concentration of sea salt $\mathrm{CCN}$ increase the reflection of solar radiation by increasing cloud optical thickness. A new cloud overlap scheme, PICA, contributes to a reduction in solar radiation reflection over the tropics without changing the cloud cover. These modifications in MRI-ESM2 significantly reduce the large bias in the solar radiation reflection present in MRI-CGCM3, which is negative over the Southern Ocean and positive over the tropics (Figs. 1e, f and 11c). Note that the significant improvement in the shortwave radiative flux is not attributed to the introduction of a new advanced scheme but to the cumulative effect of many minor modifications.

\subsection{Comments on tuning}

At the end of this section, we give a brief description of the model tuning related to clouds. At a stage of developing schemes, a number of AMIP type simulations (with a typical 1-year length) were performed using atmospheric and aerosol coupled models to check the basic behavior of schemes and the basic impacts on radiative fluxes. At a tuning stage, 5-year runs of AMIP type simulations were mainly examined. The main targets for tuning parameters related to clouds in MRI-ESM2 were global-mean biases and root-mean square errors of shortwave and longwave radiative fluxes at the top of the atmosphere. The tuning parameters related to clouds are parameters which affect cloud properties differently by cloud types and control these cloud prop- 


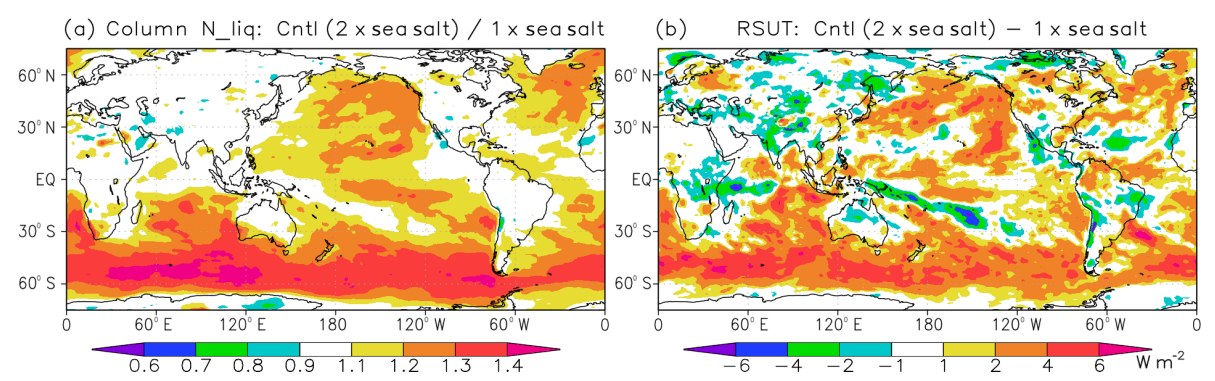

Figure 9. Impacts of doubled number concentration of sea salt $\mathrm{CCN}$ on (a) the column-integrated number concentration of cloud droplets (unitless) and (b) the TOA upward shortwave radiative flux $\left(\mathrm{W} \mathrm{m}^{-2}\right)$. The panels show the ratio (a) and the difference (b) between results for the control model (doubled number concentration of sea salt $\mathrm{CCN}$ ) and those for an experiment using the original number concentration of sea salt $\mathrm{CCN}$.
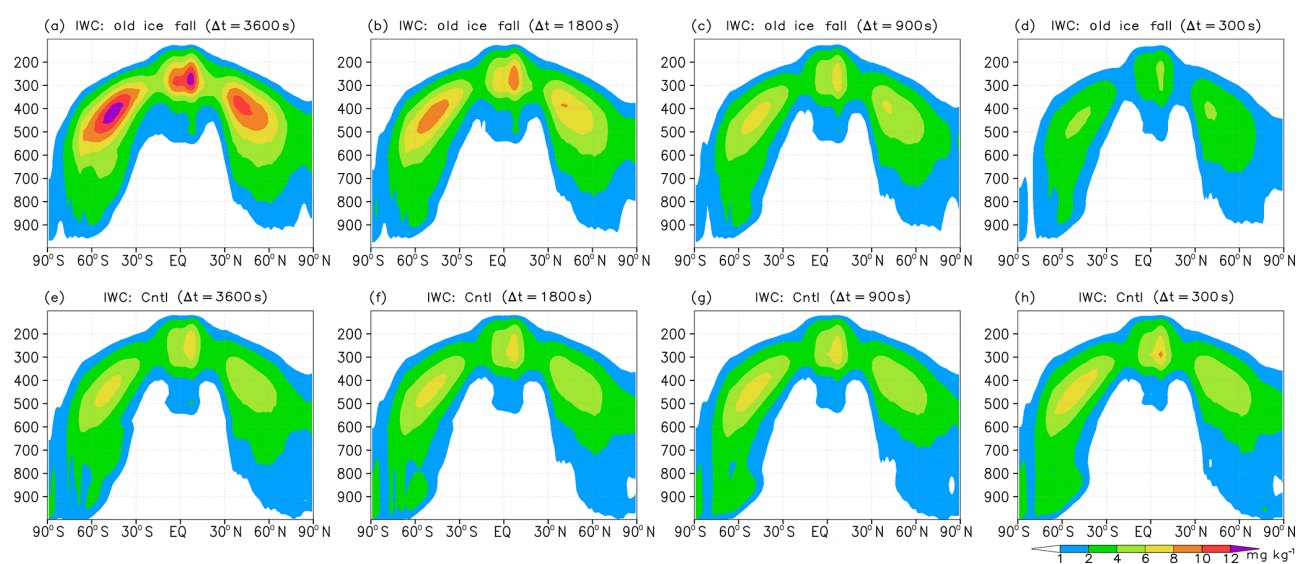

Figure 10. Zonal average of ice water content $\left(\mathrm{mg} \mathrm{kg}^{-1}\right)$ for different model time steps. Panels (a, $\left.\mathbf{b}, \mathbf{c}, \mathbf{d}\right)$ show results using the old ice fall scheme and panels $(\mathbf{e}, \mathbf{f}, \mathbf{g}, \mathbf{h})$ the control simulation using the modified ice fall scheme. From left to right, the time steps are $3600,1800,900$ and $300 \mathrm{~s}$. The vertical axis shows air pressure $(\mathrm{hPa})$ and the horizontal axis shows latitude.

erties, such as cloud cover, cloud water content and cloud number concentration. In the stratocumulus parameterization (Sect. 3.1), the threshold value of estimated cloud top entrainment index (ECTEI) was tuned to increase Southern Ocean clouds as described in Sect. 4.1.3. The relatively large mode radius of sulfate of $0.10 \mu \mathrm{m}$ (possible range: 0.05 $0.10 \mu \mathrm{m}$ ) was chosen to obtain a smaller cloud droplet number concentration to prevent excessive aerosol-cloud interaction. Treatment of the WBF effect (Sect. 3.2), cloud overlap scheme (Sect. 3.5), schemes for ice sedimentation and ice conversion to snow (Sect. 3.9), and others (Sect. 3.3, 3.4, 3.6 and 3.7) were not tuned. Descriptions of the model tuning (other than cloud-related parameters) are given in Yukimoto et al. (2019).

\section{Detailed description of schemes}

In this section, modifications and improvements in two schemes are explained in detail because they include scientifically new concepts and technically important insights and solutions related to the numerical issues; one is the new stratocumulus parameterization and the other is the improved cloud ice fall scheme.

\subsection{New stratocumulus parameterization}

\subsubsection{Old parameterization and problems}

In MRI-CGCM3, a stratocumulus scheme slightly modified from Kawai and Inoue (2006), originally developed from Slingo $(1980,1987)$, was used to represent subtropical stratocumulus. In that scheme, stratocumulus is formed when the following four conditions are met: (i) there is a strong inversion above the model layer, (ii) the layer near the surface is not stable (to guarantee existence of a mixed layer), (iii) the model layer height is below the level of $940 \mathrm{hPa}$, and (iv) the relative humidity of the model layer exceeds $80 \%$. When all of these conditions are met, cloud cover is determined as a function of the inversion strength, in-cloud cloud water content is determined to be proportional to the saturation specific humidity and the vertical mixing at the top of the cloud layer is reduced to approximately zero to prevent excess cloud top entrainment. 

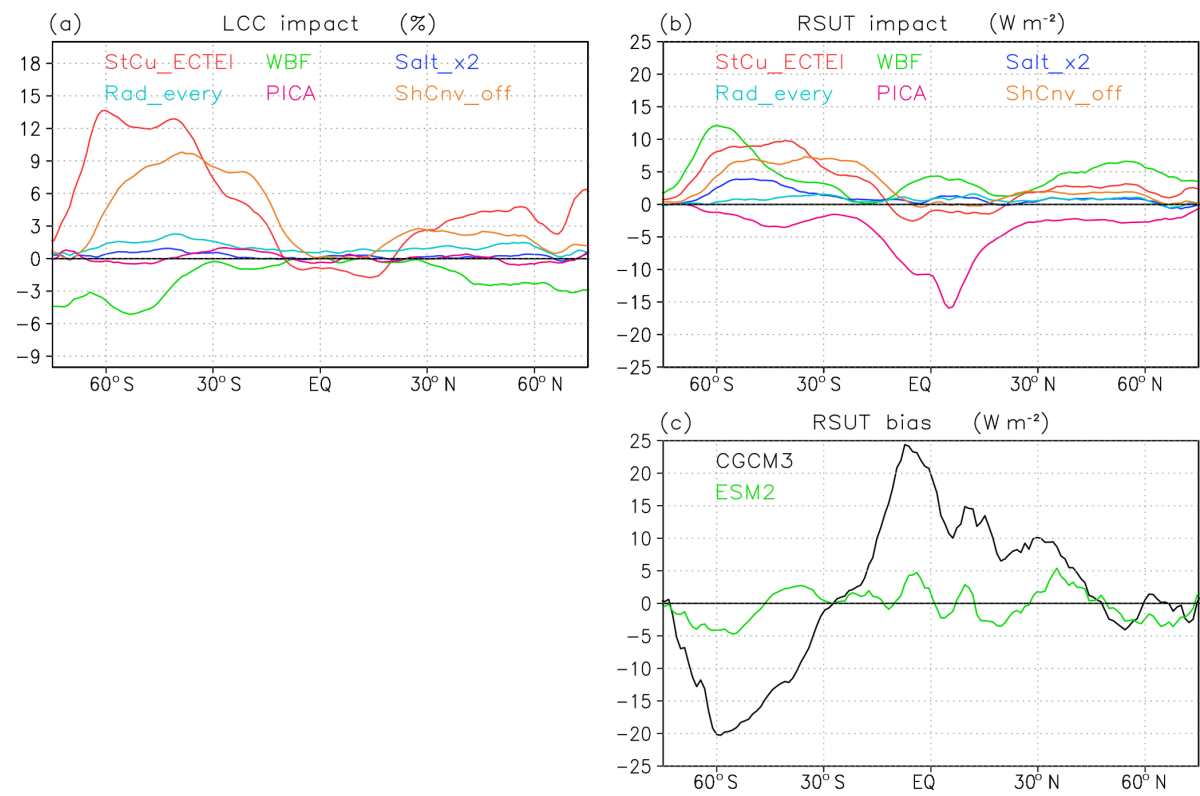

Figure 11. Impacts of each modification on zonal means of (a) low-cloud cover (\%) and (b) TOA upward shortwave radiative flux (W $\mathrm{m}^{-}$). Modifications include a new stratocumulus scheme (red line), the new treatment of the WBF effect (green), doubled number concentration of sea salt CCN (blue), increased horizontal resolution for radiation calculation (light blue), a new cloud overlap scheme, PICA (pink), and a treatment of shallow convection suppressed under stratocumulus conditions (orange). Each impact is calculated from the simulation data described in Sect. 2.3. The biases in TOA upward shortwave radiative flux for MRI-CGCM3 (black line) and MRI-ESM2 (green) are also shown in (c), where the data used are the same as in Fig. 1.

Although this scheme can reproduce subtropical stratocumulus and the cloud radiative effect relatively well, it has several problems. First, it does not give enough low clouds over midlatitude oceans, especially in the Southern Ocean. Low clouds off the west coast of the continents, including off California, off Peru and off Namibia, are also insufficient, especially areas far from the coast. The second problem is related to the use of inversion strength in parameterization in climate models, which is calculated from the difference of potential temperature between two adjacent vertical model layers. Climate models cannot reproduce realistic strong inversions because their vertical resolution is totally insufficient. Furthermore, the inversion strength reproduced in climate models strongly depends on the model vertical resolution. Therefore, the parameter has to be tuned for each model if the inversion strength is directly utilized in the parameterization. In addition, there is a strong positive feedback between the cloud fraction of low cloud and the inversion strength at the top of the cloud. The positive feedback makes it difficult to utilize inversion strength in the parameterization of the low-cloud fraction. The third problem is that the vertical structure with a smooth transition from stratocumulus to cumulus cannot be reproduced because the parameterization is limited to below the level of $940 \mathrm{hPa}$ (see Kawai and Inoue, 2006). To solve these problems, we decided to utilize a criterion that represents the structure of the lower troposphere as a whole ("non-local") rather than a detailed local vertical structure.

\subsubsection{New index for low-cloud cover}

Estimated inversion strength (EIS; Wood and Bretherton, 2006), which is a modification of lower tropospheric stability (LTS; Klein and Hartmann, 1993), is an index that correlates well with low-cloud cover and has been used in many studies. However, EIS takes into account only the temperature profile and does not include information on water vapor. Kawai et al. (2017) developed an index for low-cloud cover, the ECTEI. This index is deduced from a criterion of cloud top entrainment (Randall, 1980; Deardorff, 1980; Kuo and Schubert, 1988; Betts and Boers, 1990; MacVean and Mason, 1990; MacVean, 1993; Yamaguchi and Randall, 2008; Lock, 2009) and includes information on both the vertical profile of temperature and that of water vapor. The definition of ECTEI is as follows:

$\mathrm{ECTEI} \equiv \mathrm{EIS}-\beta L / c_{p}\left(q_{\mathrm{surf}}-q_{700}\right)$,

where $L$ is latent heat, $c_{p}$ is the specific heat at constant pressure, $q_{\text {surf }}$ and $q_{700}$ are the specific humidity at the surface and $700 \mathrm{hPa}$, respectively, $\beta=(1-k) C_{\mathrm{qgap}}, C_{\mathrm{qgap}}$ is a coefficient $(=0.76)$, and $k$ is a constant $(=0.70$; MacVean and Mason, 1990).

Figure 12 shows the climatologies of low stratiform cloud cover and the stability indexes LTS, EIS and ECTEI for December to February and June to August. Cloud cover data were obtained from shipboard observations, the extended edited cloud report archive (EECRA; Hahn and War- 
ren, 2009), and stability indexes were calculated using the ECMWF 40-year Re-Analysis (ERA-40) data (Uppala et al., 2005) for 1957-2002. The definition of low-cloud cover (LCC) in the observations is the combined cloud cover of stratocumulus, stratus and sky-obscuring fog, which is the same conventional definition as employed in Klein and Hartmann (1993) and Wood and Bretherton (2006). When LCC and LTS maps are compared, the contrast between the subtropics and midlatitudes is different. LTS is weighted more over the subtropics than over midlatitudes while LCC is dominant over midlatitudes. In EIS maps, the value is more weighted in midlatitudes than in the subtropics, compared with LTS, and the EIS geographical patterns are closer to LCC patterns than LTS patterns, as it is well-known that EIS corresponds to LCC better than LTS. In ECTEI maps, the weight is even larger in midlatitudes than for EIS and the ECTEI geographical patterns are even closer to LCC patterns than the EIS patterns. These characteristics suggest that EIS does not adequately represent the large occurrence of low cloud over cold oceans including the Southern Ocean and ECTEI can be more appropriate for the representation of LCC. Figure 13 shows the relationships between the LCC and the stability indexes: LTS, EIS and ECTEI. It shows that ECTEI has the best correlation with LCC with correlation coefficients $R=0.23$ for LTS, $R=0.83$ for EIS and $R=0.90$ for ECTEI.

\subsubsection{New parameterization and improvements}

In our new scheme, the relationship between ECTEI and LCC is not directly used, but ECTEI is used as a threshold of a treatment in the turbulence scheme. In our climate models, vertical smoothing of vertical diffusivity is employed to represent simply the mixing effect due to cloud top entrainment and part of the mixing due to shallow convection. In MRI-ESM2, if ECTEI is larger than a threshold value, the smoothing is prevented, which means the turbulence at the top of the boundary layer is suppressed, and the lower limit of vertical diffusivity is set to a much smaller value (virtually zero) than the original one. This means that cloud top entrainment in the model is switched on and off depending on an ECTEI threshold. In the original setting, the threshold value was set to $0 \mathrm{~K}$ and the condition of a non-stable near-surface layer (to guarantee existence of a mixed layer) was imposed (Kawai, 2013). However, after model tuning, the threshold value of ECTEI was set to $-2.0 \mathrm{~K}$ (possible range: -3.0 to $+3.0 \mathrm{~K}$ ), and the condition of mixed-layer existence was removed to apply the suppression of cloud top mixing not only to stratocumulus conditions but also to advection fog conditions, where the near-surface layer is stable. The introduction of this scheme has led to an increase in low-cloud cover, especially over the midlatitude ocean, including the Southern Ocean, and the radiation bias is significantly reduced (Fig. 3).

The application of a condition that represents the detailed local vertical structure may appear to be more physically based than a non-local condition. However, parameterizations based on local vertical structures are not appropriate in some cases where (i) model resolution is not sufficient to represent the detailed physical process or (ii) the feedback between the parameters and the variables that should be obtained is very strong. In such cases, the parameters that represent the whole structure of the lower troposphere can produce more robust and reasonable results, although empirical relations are required to construct non-local parameterizations.

\subsubsection{Brief discussion on climate change simulations}

It is well-known that changes in LCC in warmer climates cannot be explained by changes in LTS (e.g., Williams et al., 2006; Medeiros et al., 2008; Lauer et al., 2010). The mechanism of this discrepancy is also well-understood; an inevitable decrease in moist adiabatic lapse rate in the free atmosphere in warmer climates causes an increase in LTS (e.g., Miller, 1997; Larson et al., 1999), even though the inversion strength that probably contributes to determining LCC does not change (e.g., Wood and Bretherton, 2006; Caldwell and Bretherton, 2009). It was expected that an index EIS could avoid this problem and could be used for the discussion of LCC changes under warmer climates because EIS is a more physics-based index that represents inversion strength at the cloud top more directly. However, more recently, it turned out that LCC tends to decrease, although EIS increases in warmer climates in most climate models (e.g., Webb et al., 2013). Subsequently, it was shown by Qu et al. (2014) that changes (including variations in the present climate and future changes) in LCC can be determined by a linear combination of changes in EIS (positive correlation) and SST (negative correlation). Kawai et al. (2017) derived the linear combination from the index ECTEI and showed that a decrease in LCC under increased EIS in warmer climates can be explained based on the ECTEI change (see Kawai et al., 2017, for more detail). It is true that using empirical relationships obtained in the present climate for climate change simulations has the possibility of causing spurious climate feedback. On the other hand, we would like to note that although the risk of spurious climate feedback still cannot be eliminated, (i) ECTEI is an even more physicsbased index than EIS, (ii) the relationship is not used directly for cloud formation but used as a threshold for cloud top mixing, and (iii) ECTEI can explain positive low-cloud feedback.

\subsection{Ice sedimentation and ice conversion to snow}

\subsubsection{Old treatment and problems}

Treatment of ice sedimentation in climate models is awkward because the product of the terminal velocity of cloud ice $v_{\text {ice }}$ (typical value $\sim 0.5 \mathrm{~m} \mathrm{~s}^{-1}$ ) and the time step $\Delta t$ (for example, $1800 \mathrm{~s}$ in MRI-CGCM3 and MRI-ESM2) can exceed the thickness of the vertical layer $\Delta z(\sim 500 \mathrm{~m})$ in climate 

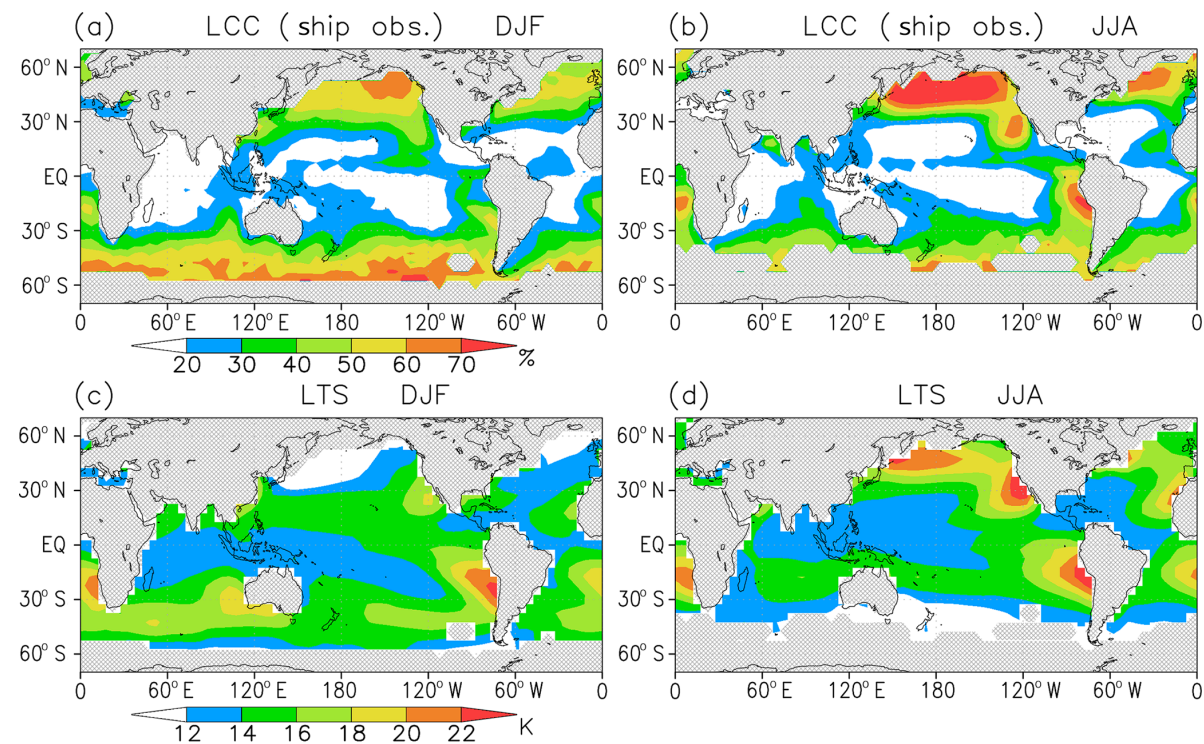

(e)

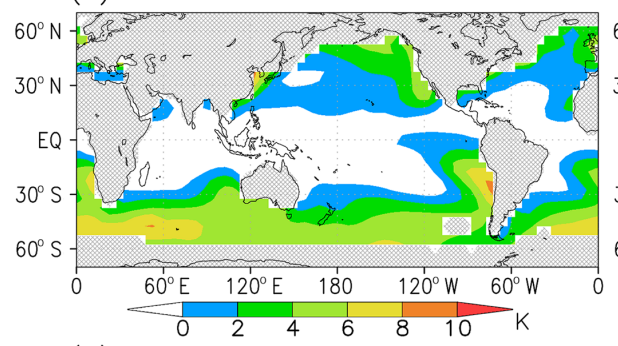

(g)

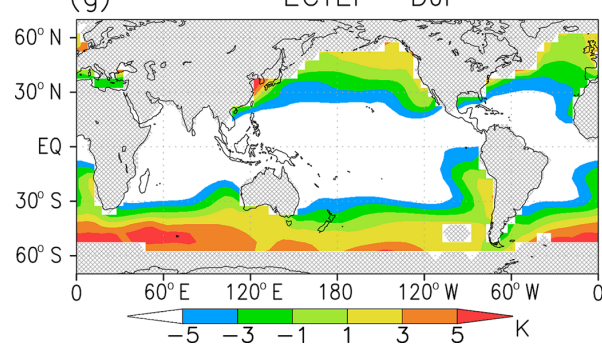

(f)

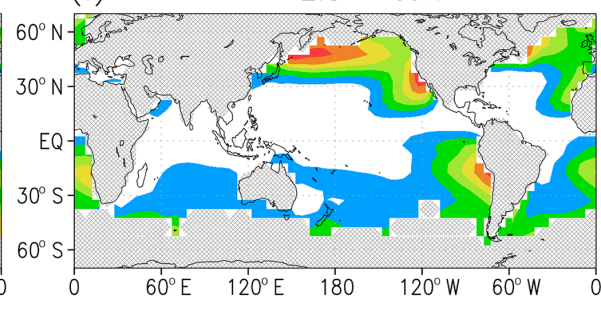

(h)

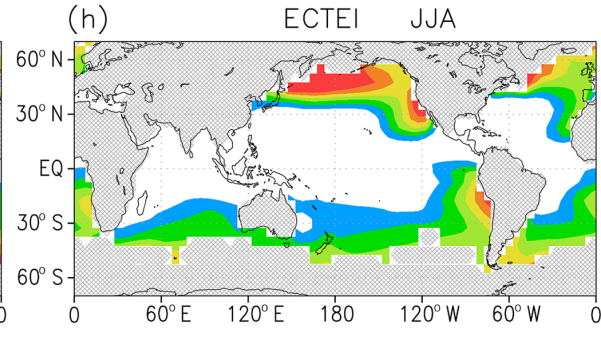

Figure 12. Climatologies of low stratiform cloud cover (\%), LTS (K), EIS (K) and ECTEI (K) for December to February (a, c, e, g) and June to August $(\mathbf{b}, \mathbf{d}, \mathbf{f}, \mathbf{h})$. Cloud cover data were obtained from EECRA shipboard observations, and stability indexes were calculated using ERA-40 data (1957-2002).

(a)

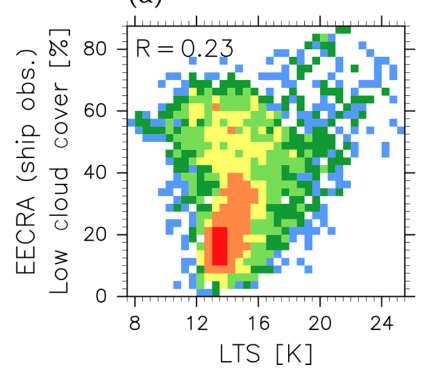

(b)

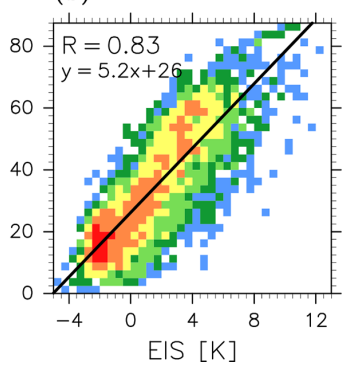

(c)

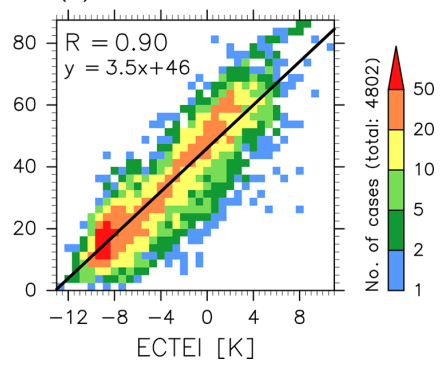

Figure 13. Frequencies of the occurrence of low stratiform cloud cover (combined cloud cover of stratocumulus, stratus and sky-obscuring fog) sorted by (a) LTS, (b) EIS and (c) ECTEI $(\beta=0.23)$, based on all $5^{\circ} \times 5^{\circ}$ seasonal climatology data. Data are the same as in Fig. 12 , but all the data between $60^{\circ} \mathrm{N}$ and $60^{\circ} \mathrm{S}$ for all seasons were used. Linear regression lines and the correlation coefficients are shown. 
models. In such cases the explicit calculation is invalid and numerical instability may occur because a vertical CourantFriedrichs-Lewy (CFL) condition is violated. To avoid this problem, various measures have been taken. Rotstayn (1997) reviewed the following four treatments: (a) to set an artificial limit to the sedimentation flux for preventing defective calculation; (b) to adopt a "fall-through" assumption; (c) to use an implicit scheme; and (d) to use an analytically integrated scheme. Discussing the problems associated with each treatment, he concluded that the last one (d) was the most suitable. Although adopting shorter time steps for selected processes, which is called sub-stepping (e.g., Morrison and Gettelman, 2008), would be an ideal solution, it can increase computational cost to some degree.

In MRI-CGCM3, IWC was divided into ice crystals and snow using a size threshold of $100 \mu \mathrm{m}$. The size distribution of ice particles is assumed to follow a Marshall-Palmer distribution as described in Rotstayn (1997):

$P_{\mathrm{i}}\left(D_{\mathrm{i}}\right)=\lambda_{\mathrm{i}} e^{-\lambda_{\mathrm{i}} D_{\mathrm{i}}}$,

where $D_{\mathrm{i}}(\mathrm{m})$ is the diameter of ice particles, $\lambda_{\mathrm{i}}\left(\mathrm{m}^{-1}\right)$ is the slope factor and the distribution $P_{\mathrm{i}}\left(D_{\mathrm{i}}\right)$ is normalized to 1 . The slope factor can be written as follows:

$\lambda_{\mathrm{i}}=\left(\frac{\pi \rho_{\mathrm{i}} N_{\mathrm{i}}}{\rho_{\mathrm{a}} q_{\mathrm{i}}}\right)^{1 / 3}$,

where $\rho_{\mathrm{i}}\left(\mathrm{kg} \mathrm{m}^{-3}\right)$ is the density of ice, $N_{\mathrm{i}}\left(\mathrm{m}^{-3}\right)$ is the number concentration of ice crystals, $\rho_{\mathrm{a}}\left(\mathrm{kg} \mathrm{m}^{-3}\right)$ is air density and $q_{\mathrm{i}}\left(\mathrm{kg} \mathrm{kg}^{-1}\right)$ is IWC. The ratios of cloud ice crystals with a size less than $100 \mu \mathrm{m}$ with respect to total ice crystals can be obtained analytically by integrating the probability density function as follows:

$$
\begin{aligned}
r_{\mathrm{iw}} & =1-\frac{1}{6}\left\{\left(\lambda_{\mathrm{i}} D_{100}\right)^{3}+3\left(\lambda_{\mathrm{i}} D_{100}\right)^{2}\right. \\
& \left.+6\left(\lambda_{\mathrm{i}} D_{100}\right)+6\right\} e^{-\lambda_{\mathrm{i}} D_{100}}, \\
r_{\mathrm{in}} & =1-e^{-\lambda_{\mathrm{i}} D_{100}},
\end{aligned}
$$

where $D_{100}(\mathrm{~m})$ is particle size of $1 \times 10^{-4}(\mathrm{~m})(=100 \mu \mathrm{m})$, and $r_{\text {iw }}$ and $r_{\text {in }}$ are ratios of cloud ice crystals for mass and number concentrations. A sedimentation velocity $\left(\mathrm{m} \mathrm{s}^{-1}\right)$ is calculated based on Heymsfield (1977), Heymsfield and Donner (1990), and Rotstayn (1997):

$v_{\text {ice }}=3.23\left(\frac{\rho_{\mathrm{a}} q_{\mathrm{i}} r_{\mathrm{iw}}}{a}\right)^{0.17}$,

where $a$ is cloud fraction. Ice crystals of $r_{\mathrm{iw}} q_{\mathrm{i}}$ fall with sedimentation velocity $v_{\text {ice }}$, and snow mass $\left(1-r_{\text {iw }}\right) q_{\mathrm{i}}$ is assumed to fall down to the surface within a time step. The removal of the snow part based on this kind of diagnostic partition is used in some cloud schemes. In version CY25r1 of the ECMWF IFS (ECMWF, 2002), IWC is divided into two categories with sizes larger and smaller than $100 \mu \mathrm{m}$ following a function in McFarquhar and Heymsfield (1997; hereafter, MH97), and the larger size portion of IWC is considered to fall through to the ground within a time step. In MRICGCM3, the equation of IWC to be solved is as follows:

$\frac{\partial q_{\mathrm{i}}}{\partial t}=C_{\mathrm{g}}+\frac{R_{\mathrm{i}}}{\rho_{\mathrm{a}} \Delta z}-\frac{v_{\text {ice }}}{\Delta z} r_{\mathrm{iw}} q_{\mathrm{i}}-\frac{\left(1-r_{\mathrm{iw}}\right) q_{\mathrm{i}}}{\Delta t}$,

where $C_{\mathrm{g}}\left(\mathrm{kg} \mathrm{kg}^{-1} \mathrm{~s}^{-1}\right)$ is the generation rate of IWC, $R_{\mathrm{i}}$ $\left(\mathrm{kg} \mathrm{m}^{-2} \mathrm{~s}^{-1}\right)$ is the ice sedimentation flux into the layer from above, $\Delta z(\mathrm{~m})$ is the layer thickness and $\Delta t(\mathrm{~s})$ is the model time step. The second and the third terms on the right-hand side correspond to the ice sedimentation calculation (e.g., Smith, 1990; Rotstayn, 1997). An analytically integrated solution (Rotstayn, 1997; ECMWF, 2002) was used to obtain IWC after one time step.

However, this treatment presents some problems. The first is that a part of cloud ice larger than $100 \mu \mathrm{m}$ is eliminated from the atmosphere repeatedly when a short time step is used because the shape of the size distribution and the ratio of ice portions larger than and smaller than $100 \mu \mathrm{m}$ is insensitive to IWC change. This causes strong time-step dependency of IWC: IWC monotonically decreases with shorter time steps from 3600 to $300 \mathrm{~s}$ as seen in Fig. 10. The second problem is that the sedimentation velocity calculated from Eq. (1) is too large for ice with a size smaller than $100 \mu \mathrm{m}$. This is because the sedimentation velocity is supposed to represent a weighted value for the whole ice content that includes all sizes of ice, and sedimentation velocity varies widely with particle size.

\subsubsection{New scheme and improvements}

Considering the wide range of sedimentation velocity, the velocities of falling cloud ice representing both small and large particles are derived separately (originally reported in a preliminary report - Kawai, 2005). Observed size-distribution functions of cloud ice of MH97 and size-velocity relationships for cloud ice (Heymsfield and Iaquinta, 2000) were integrated over size using a procedure similar to Zurovac-Jevtić and Zhang (2003). See Supplement for the detailed derivation. While they derived only one velocity representing the total cloud ice, two velocities are derived in this study for a more sophisticated treatment of sedimentation. The ice-fall velocity for particles smaller (larger) than $100 \mu \mathrm{m}, v_{\mathrm{i}}\left(v_{\mathrm{s}}\right)$ $\left(\mathrm{m} \mathrm{s}^{-1}\right)$, is obtained as a function of ice water content smaller (larger) than $100 \mu \mathrm{m}-\mathrm{IWC}_{<100}\left(\mathrm{IWC}_{>100}\right)\left(\mathrm{kg} \mathrm{m}^{-3}\right)-$ as below (note that the unit is not kilogram per kilogram but kilogram per cubic meter):

$$
\begin{aligned}
& v_{\mathrm{i}}=1.56\left(\mathrm{IWC}_{<100}\right)^{0.24}, \\
& v_{\mathrm{s}}=2.23\left(\mathrm{IWC}_{>100}\right)^{0.074} .
\end{aligned}
$$

Figure 14 shows the velocities $v_{\mathrm{i}}$ and $v_{\mathrm{s}}$. The velocity of cloud ice smaller than $100 \mu \mathrm{m}$ is much smaller than the conventionally used velocity of ice of Rotstayn (1997). Therefore, it is inappropriate to represent the velocity of ice with 


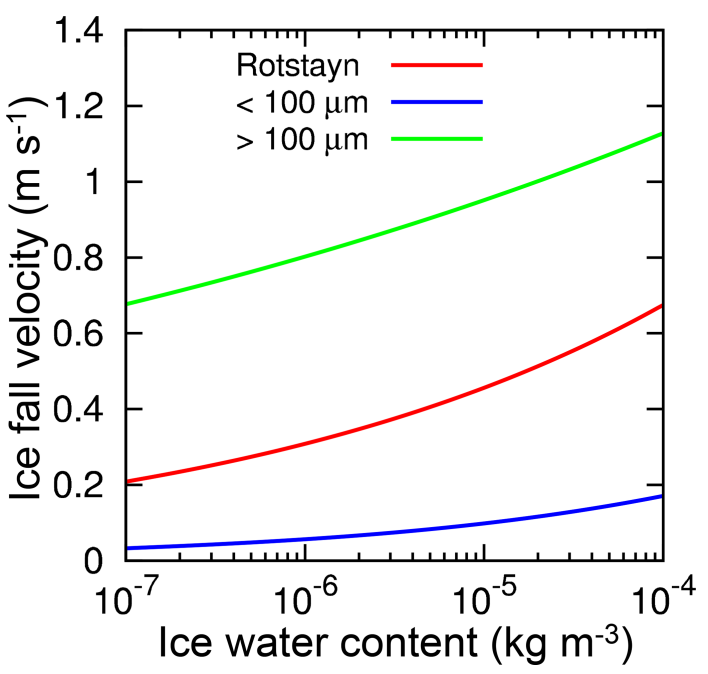

Figure 14. Ice sedimentation velocities $\left(\mathrm{m} \mathrm{s}^{-1}\right)$ of Rotstayn (1997) (Eq. 1, red line), derived for particles smaller than $100 \mu \mathrm{m}(\mathrm{Eq} \mathrm{3}$, blue line) and for particles larger than $100 \mu \mathrm{m}$ (Eq. 4, green line). The horizontal axis shows ice water mass density $\rho_{\mathrm{a}} q_{\mathrm{i}}\left(\mathrm{kg} \mathrm{m}^{-3}\right)$.

a size smaller than $100 \mu \mathrm{m}$ using the velocity of Eq. (1), and Eq. (3) is more appropriate for calculating the velocity. The figure also shows that cloud ice larger than $100 \mu \mathrm{m}$ has a velocity of about $1 \mathrm{~m} \mathrm{~s}^{-1}$. Therefore, the sedimentation cannot be calculated appropriately with the time step used in our climate models, and the treatment of instant fall of snow (large ice) through to the surface is unavoidable, unless substepping is introduced.

In MRI-CGCM3, it was assumed that the ratio of snow calculated from the Marshall-Palmer distribution can be applied anytime and anywhere without taking account of the history of the cloud processes. In this case, the conversion of ice crystal into snow is not proportional to model time step, and it causes the strong time-step dependency of IWC. If a conversion rate of ice crystals into snow is available, we can avoid this time-step dependency. To obtain the rate, we assume that the ratio given by MH97 may be regarded as a ratio between ice crystals and accumulated snow from the layers above, which is converted from ice crystals at a certain rate. In this concept, the ratio of snow should increase as the depth from the cloud top increases. In the derivation of the rate $C_{\mathrm{I} 2 \mathrm{~S}}\left(\mathrm{~kg} \mathrm{~kg}^{-1} \mathrm{~s}^{-1}\right)$, simple assumptions were introduced: (a) the concentration of cloud ice is vertically homogeneous; (b) produced snow concentration is accumulated downward; (c) the observation depth of the ratio is $H_{\mathrm{c}}(\mathrm{m})$ from the top of a cloud. Under these assumptions, the rate can be obtained as follows (see Appendix A for the derivation):

$C_{\mathrm{I} 2 \mathrm{~S}}=\frac{1-\alpha_{\mathrm{i}}}{\alpha_{\mathrm{i}}} \frac{v_{\mathrm{s}}}{H_{\mathrm{c}}} q_{\mathrm{i}}$,

where $\alpha_{i}$ is the ratio of cloud ice content with particle sizes smaller than $100 \mu \mathrm{m}$ to the total cloud ice content (see
Sect. S2 for details: Fig. S2 shows $\alpha_{\mathrm{i}}$ and the equation is Eq. S10). In this study, $H_{\mathrm{c}}=2000 \mathrm{~m}$ is assumed in reference to MH97. The equation of IWC to be solved is as follows:

$\frac{\partial q_{\mathrm{i}}}{\partial t}=C_{\mathrm{g}}+\frac{R_{\mathrm{i}}}{\rho_{\mathrm{a}} \Delta z}-\frac{v_{\mathrm{i}}}{\Delta z} q_{\mathrm{i}}-D_{\mathrm{I} 2 \mathrm{~S}} q_{\mathrm{i}}$,

where $D_{\mathrm{I} 2 \mathrm{~S}}=C_{\mathrm{I} 2 \mathrm{~S}} / q_{\mathrm{i}}$. Note that although the ratio $\alpha_{\mathrm{i}}$ obtained from Eq. (S10) is used to calculate the conversion rate $C_{\mathrm{I} 2 \mathrm{~S}}$, it is not used to directly determine the ratio between small ice crystals and snow differently from in Eq. (2). An analytically integrated solution is used to obtain IWC after one time step.

Figure 10 shows that IWC is not affected by time step in the control simulation that uses the modified scheme of ice sedimentation and ice conversion to snow, while the old scheme that was used in MRI-CGCM3 shows strong timestep dependency. The improvement can mainly be attributed to the fact that the conversion of ice to snow is proportional to the time step: the last term of the right-hand side in Eq. (6) does not explicitly depend on $\Delta t$, while the one in Eq. (2) does. In addition, the slower sedimentation velocity in the new formulation contributes to more reasonable calculation of ice crystal sedimentation because processes with short timescales compared to the model time step may be unphysically calculated. In many climate models, the terminal velocity of cloud ice has been represented by a single velocity whose typical value is $\sim 0.5 \mathrm{~m} \mathrm{~s}^{-1}$ (e.g., Heymsfield, 1977; Heymsfield and Donner, 1990), and the whole cloud ice content in the grid box falls with that velocity (e.g., Rotstayn, 1997; Smith, 1990). However, as is evident from Fig. 14, the velocity of ice crystals smaller than $100 \mu \mathrm{m}$ is $\sim 0.1 \mathrm{~m} \mathrm{~s}^{-1}$ and much smaller than the typical value representing all sizes $\left(\sim 1 \mathrm{~m} \mathrm{~s}^{-1}\right)$. Small size ice crystals should remain in the air for longer. On the other hand, some models diagnose the removal of snow portion from the total IWC assuming a fixed size distribution without taking the history of the cloud processes into account (e.g., ECMWF, 2002). However, this causes time-step dependency, as discussed above. Note also that the size distribution must change depending on the distance from the cloud top, although such dependence is not taken into account explicitly in most studies or treatments in climate models. We have clarified such problems and proposed a practical solution for them in the present paper.

\section{Summary}

In the development of the climate model MRI-ESM2 that is planned for use in CMIP6 and CFMIP-3 simulations, the representations of clouds are significantly improved from the previous version MRI-CGCM3 used in CMIP5 and CFMIP2 simulations. The score of the spatial pattern of radiative fluxes at the top of the atmosphere for MRI-ESM2 is better than any of the 48 CMIP5 models. In this paper, we presented comprehensively various modifications related to 
clouds, which contribute to the improved cloud representation, and their main impacts. The modifications cover various schemes and processes including the cloud scheme, turbulence scheme, cloud microphysics processes, the interaction between cloud and convection schemes, resolution issues, cloud radiation processes, the aerosol properties, and numerics. Note that the improvement of performance in climate models due to an update is ordinarily contributed by the cumulative effect of many minor modifications rather than by the introduction of a new advanced scheme. In addition, the new stratocumulus parameterization and improved cloud ice fall scheme are described in detail because they include scientifically new concepts and technically important issues. As a result, this paper will be useful for model developers and users of our CMIP6 outputs, especially those related to clouds.

The most remarkable improvement addressed the serious lack of upward shortwave radiative flux over the Southern Ocean in the old version. This improvement was obtained mainly by (i) an increase in low-cloud cover due to the implementation of the new stratocumulus scheme, a new treatment of the suppression of shallow convection under stratocumulus conditions, and increased horizontal resolution for the radiation calculation; (ii) an increase in the ratio of supercooled liquid water due to the modified treatment of the WBF effect; and (iii) an increase in cloud droplet number concentration by taking the effect of small size sea-salt aerosols into account. Items (ii) and (iii) contribute to an increase in the optical thickness of clouds. The excessive reflection of solar radiation over the tropics in MRI-CGCM3 was substantially reduced by the introduction of a new cloud overlap scheme, PICA. Increased vertical resolution from L48 to L80 and a treatment of the suppression of shallow convection under stratocumulus conditions contribute to improving the vertical structure of the transition from subtropical stratocumulus to cumulus. In addition, improved treatments of cloud ice sedimentation and conversion of cloud ice to snow, which are based on more accurate physics than the old ones, alleviated the strong time-step dependency of IWC.
However, the modifications in MRI-ESM2 are still relatively simple and ad hoc in some cases. Therefore, we should continue to develop various schemes and processes related to clouds, especially cloud microphysics and the treatment of cloud inhomogeneity within a model grid box, by introducing more sophisticated concepts.

On a final note, we acknowledge the many evaluation and intercomparison studies related to clouds for CMIP multimodels, which have given us useful information for model development (e.g., Jiang et al., 2012, for vertical profiles of cloud water content and water vapor; Lauer and Hamilton, 2013, for liquid water path; Su et al., 2013, for vertical profiles of cloud fraction and cloud water content under different large-scale environments; McCoy et al., 2015, and Cesana et al., 2015, for ratios of supercooled liquid water and ice; Nam et al., 2012, for cloud radiative effect and vertical structure of low clouds; Nuijens et al., 2015, for vertical structures and temporal variations of trade-wind cumulus; BodasSalcedo et al., 2014, for cloud and radiation biases over the Southern Ocean; Kawai et al., 2018, for marine fog; Suzuki et al., 2015, for warm rain formation process; Tsushima et al., 2013, for occurrence frequency and cloud radiative effect of each cloud regime). It is impossible for a modeler to examine all of these characteristics in their own model because there are many aspects to examine even for cloud-related values alone and these evaluations need specific knowledge and careful treatment. Therefore, these evaluation activities are very helpful for modellers to improve and develop their models.

Code and data availability. Access to the simulation data can be granted upon request. The MRI-ESM2 code is the property of MRI/JMA and not available to the general public. Access to the code can be granted upon request, under a collaborative framework between MRI and related institutes or universities. 
Appendix A: Derivation of the conversion rate of cloud ice crystals to snow

The conversion rate of cloud ice crystals to snow (cloud ice particles whose size is larger than $100 \mu \mathrm{m}$ are called "snow" here) in the new treatment is derived under the simple assumptions described below. Although these assumptions are rather rough, the advantage is that this rate utilized in the scheme is derived from observational relationships for tropical cirrus.

It is assumed that the ratio between cloud ice crystals and snow is not the same throughout a cloud but depends on the depth from the cloud top. It is presumed that the ratio of small cloud ice crystals is large near the cloud top and the ratio of snow (large cloud ice) increases downward in the cloud because upper cloud ice crystals are continuously converted to snow and the density of snow, which falls with a velocity much faster than cloud ice crystals, is accumulated downward. Therefore, the ratios should be a function of the distance from the cloud top, and the ratios $\alpha_{\mathrm{i}}$ in MH97 should be regarded as the ratio at a certain distance from the cloud top.

To derive the conversion rate in this study, cloud ice content $q_{\mathrm{i}}\left(\mathrm{kg} \mathrm{kg}^{-1}\right)$ was assumed to be vertically homogeneous in the cloud. The snow density $\left(\mathrm{kg} \mathrm{m}^{-3}\right)$ that is produced by a unit volume of cloud ice crystals existing at upper altitude is $C_{\mathrm{I} 2 \mathrm{~S}} \rho_{\mathrm{a}} v_{\mathrm{s}}^{-1}$, using a conversion rate of cloud ice to snow $C_{\text {I2S }}\left(\mathrm{kg} \mathrm{kg}^{-1} \mathrm{~s}^{-1}\right)$. Consequently, the snow density at height $z$ can be written as follows, using the cloud top height $z_{\text {ctop }}$.

$$
\int_{z}^{z_{\text {ctop }}} C_{\mathrm{I} 2 \mathrm{~S}} \frac{\rho_{\mathrm{a}}}{v_{\mathrm{S}}} \mathrm{d} z \approx \frac{z_{\text {ctop }}-z}{v_{\mathrm{S}}} \rho_{\mathrm{a}} C_{\mathrm{I} 2 \mathrm{~S}},
$$

where a constant value is used for $\rho_{\mathrm{a}}$ regardless of the height for simplicity. Then snow content per unit air mass is $C_{\mathrm{I} 2 \mathrm{~S}} H_{\mathrm{c}} v_{\mathrm{s}}^{-1}\left(\mathrm{~kg} \mathrm{~kg}^{-1}\right)$ using $H_{\mathrm{c}} \equiv z_{\mathrm{ctop}}-z$. On the other hand, the ratio of cloud ice crystals to snow can be written as follows using the observational function $\alpha_{\mathrm{i}}$ by MH97:

$q_{\mathrm{i}}: \frac{H_{\mathrm{c}}}{v_{\mathrm{S}}} C_{\mathrm{I} 2 \mathrm{~S}}=\alpha_{\mathrm{i}}: 1-\alpha_{\mathrm{i}}$.

Therefore, $C_{\mathrm{I} 2 \mathrm{~S}}$ can be derived as follows:

$C_{\mathrm{I} 2 \mathrm{~S}}=\frac{1-\alpha_{\mathrm{i}}}{\alpha_{\mathrm{i}}} \frac{v_{\mathrm{s}}}{H_{\mathrm{c}}} q_{\mathrm{i}}$. 
Supplement. The supplement related to this article is available online at: https://doi.org/10.5194/gmd-12-2875-2019-supplement.

Author contributions. HK was responsible for most aspects of model developments related to the representation of clouds. SY performed the tuning of clouds simulated in MRI-ESM2 and many sensitivity tests. TK performed coding related to aerosol optical properties and the output format of the model. NO and TT developed the aerosol model and contributed to the improvements of the aerosol radiation and aerosol cloud interactions. RN developed PICA and HY implemented the scheme into MRI-ESM2. SY and TK performed many model simulations, and TK and HY contributed to find coding problems in the original cloud scheme. All authors contributed to related discussions. HK wrote the first draft of the article, and all authors contributed to the writing of the final version of the article.

Competing interests. The authors declare that they have no conflict of interest.

Acknowledgements. We acknowledge the editor for handling this paper and the two anonymous reviewers for their supportive and insightful comments. Several datasets (Pincus et al., 2012; Zhang et al., 2012) used in this work were obtained from the obs4MIPs project (https://www.earthsystemcog.org/projects/obs4mips/, last access: 8 July 2019) hosted on the Earth System Grid Federation (http://esgf.llnl.gov, last access: 8 July 2019). Kohei Yoshida made efforts to determine vertical model levels in MRI-ESM2, and Eiki Shindo kindly supported HK in performing model experiments.

Financial support. This research has been supported by the Ministry of Education, Culture, Sports, Science and Technology (MEXT), Japan (TOUGOU program grant), the Japan Society for the Promotion of Science (JSPS) (grant nos. JP26701004, JP16H01772, JP18H05292, JP18H03363, and JP19K03977), and the Environmental Restoration and Conservation Agency, Japan (the Environment Research and Technology Development Fund (grant nos. 2-1703 and S-12)).

Review statement. This paper was edited by Axel Lauer and reviewed by two anonymous referees.

\section{References}

Abdul-Razzak, H. and Ghan, S. J.: A parameterization of aerosol activation: 2. Multiple aerosol types, J. Geophys. Res., 105, 6837, https://doi.org/10.1029/1999JD901161, 2000.

Abdul-Razzak, H., Ghan, S. J., and Rivera-Carpio, C.: A parameterization of aerosol activation: 1. Single aerosol type, J. Geophys. Res., 103, 6123, https://doi.org/10.1029/97JD03735, 1998.

Abel, S. J., Walters, D. N., and Allen, G.: Evaluation of stratocumulus cloud prediction in the Met Office forecast model during VOCALS-REx, Atmos. Chem. Phys., 10, 10541-10559, https://doi.org/10.5194/acp-10-10541-2010, 2010.

Betts, A. K.: Diurnal variation of California coastal stratocumulus from two days of boundary layer soundings, Tellus A, 42, 302-304, https://doi.org/10.1034/j.1600-0870.1990.t01-100007.x, 1990.

Betts, A. K. and Boers, R.: A Cloudiness Transition in a Marine Boundary Layer, J. Atmos. Sci., 47, 1480-1497, https://doi.org/10.1175/15200469(1990)047<1480:ACTIAM>2.0.CO;2, 1990.

Bigg, E. K.: The supercooling of water, Proc. Phys. Soc. B, 66, 688694, 1953.

Bodas-Salcedo, A., Williams, K. D., Ringer, M. A., Beau, I., Cole, J. N. S., Dufresne, J. L., Koshiro, T., Stevens, B., Wang, Z., and Yokohata, T.: Origins of the solar radiation biases over the Southern Ocean in CFMIP2 models, J. Climate, 27, 41-56, https://doi.org/10.1175/JCLI-D-13-00169.1, 2014.

Bodas-Salcedo, A., Hill, P. G., Furtado, K., Williams, K. D., Field, P. R., Manners, J. C., Hyder, P., and Kato, S.: Large contribution of supercooled liquid clouds to the solar radiation budget of the Southern Ocean, J. Climate, 29, 4213-4228, https://doi.org/10.1175/JCLI-D-15-0564.1, 2016.

Bony, S., Webb, M., Bretherton, C., Klein, S., Siebesma, P., Tselioudis, G., and Zhang, M.: CFMIP: Towards a better evaluation and understanding of clouds and cloud feedbacks in CMIP5 models, Clivar Exch., 56, 20-24, 2011.

Bretherton, C. S., Wood, R., George, R. C., Leon, D., Allen, G., and Zheng, X.: Southeast Pacific stratocumulus clouds, precipitation and boundary layer structure sampled along $20^{\circ} \mathrm{S}$ during VOCALS-REx, Atmos. Chem. Phys., 10, 10639-10654, https://doi.org/10.5194/acp-10-10639-2010, 2010.

Brooks, M. E., Hogan, R. J., and Illingworth, A. J.: Parameterizing the Difference in Cloud Fraction Defined by Area and by Volume as Observed with Radar and Lidar, J. Atmos. Sci., 62, 2248-2260, https://doi.org/10.1175/JAS3467.1, 2005.

Bushell, A. C. and Martin, G. M.: The impact of vertical resolution upon GCM simulations of marine stratocumulus, Clim. Dynam., 15, 293-318, https://doi.org/10.1007/s003820050283, 1999.

Caldwell, P. and Bretherton, C. S.: Response of a Subtropical Stratocumulus-Capped Mixed Layer to Climate and Aerosol Changes, J. Climate, 22, 20-38, https://doi.org/10.1175/2008JCLI1967.1, 2009.

Caldwell, P. M., Zhang, Y., and Klein, S. A.: CMIP3 subtropical stratocumulus cloud feedback interpreted through a mixed-layer model, J. Climate, 26, 1607-1625, https://doi.org/10.1175/JCLID-12-00188.1, 2013.

Cesana, G. and Chepfer, H.: Evaluation of the cloud thermodynamic phase in a climate model using CALIPSOGOCCP, J. Geophys. Res.-Atmos., 118, 7922-7937, https://doi.org/10.1002/jgrd.50376, 2013.

Cesana, G., Waliser, D. E., Jiang, X., and Li, J. L. F.: Multimodel evaluation of cloud phase transition using satellite and reanalysis data, J. Geophys. Res.-Atmos., 120, 7871-7892, https://doi.org/10.1002/2014JD022932, 2015.

Cesana, G., Chepfer, H., Winker, D., Getzewich, B., Cai, X., Jourdan, O., Mioche, G., Okamoto, H., Hagihara, Y., Noel, V., and Reverdy, M.: Using in situ airborne measurements to evaluate three cloud phase products derived 
from CALIPSO, J. Geophys. Res.-Atmos., 121, 5788-5808, https://doi.org/10.1002/2015JD024334, 2016.

Chin, M., Ginoux, P., Kinne, S., Torres, O., Holben, B. N., Duncan, B. N., Martin, R. V., Logan, J. A., Higurashi, A., and Nakajima, T.: Tropospheric Aerosol Optical Thickness from the GOCART Model and Comparisons with Satellite and Sun Photometer Measurements, J. Atmos. Sci., 59, 461-483, https://doi.org/10.1175/15200469(2002)059<0461:TAOTFT>2.0.CO;2, 2002.

Clarke, A. D., Owens, S. R., and Zhou, J.: An ultrafine sea-salt flux from breaking waves: Implications for cloud condensation nuclei in the remote marine atmosphere, J. Geophys. Res., 111, D06202, https://doi.org/10.1029/2005JD006565, 2006.

Collins, W. D.: Parameterization of Generalized Cloud Overlap for Radiative Calculations in General Circulation Models, J. Atmos. Sci., 58, 3224-3242, https://doi.org/10.1175/15200469(2001)058<3224:POGCOF>2.0.CO;2, 2001.

Cotton, W. R., Tripoli, G. J., Rauber, R. M., and Mulvihill, E. A.: Numerical Simulation of the Effects of Varying Ice Crystal Nucleation Rates and Aggregation Processes on Orographic Snowfall, J. Clim. Appl. Meteorol., 25, 1658-1680, https://doi.org/10.1175/15200450(1986)025<1658:NSOTEO>2.0.CO;2, 1986.

Covert, D. S., Kapustin, V. N., Bates, T. S., and Quinn, P. K.: Physical properties of marine boundary layer aerosol particles of the mid-Pacific in relation to sources and meteorological transport, J. Geophys. Res., 101, 6919-6930, https://doi.org/10.1029/95JD03068, 1996.

Deardorff, J. W.: Cloud Top Entrainment Instability, J. Atmos. Sci., 37, 131-147, https://doi.org/10.1175/15200469(1980)037<0131:CTEI>2.0.CO;2, 1980.

Duynkerke, P. G. and Teixeira, J.: Comparison of the ECMWF Reanalysis with FIRE I Observations: Diurnal Variation of Marine Stratocumulus, J. Climate, $14, \quad 1466-1478$, https://doi.org/10.1175/15200442(2001)014<1466:COTERW>2.0.CO;2, 2001.

ECMWF: Clouds and large-scale precipitation, IFS Documentation, European Centre for Medium-Range Weather Forecasts, CY25r1, Part IV, Chapter 6, 2002.

ECMWF: Clouds and large-scale precipitation, IFS Documentation, European Centre for Medium-Range Weather Forecasts, CY43r3, Part IV, Chapter 7, 2017.

Eyring, V., Bony, S., Meehl, G. A., Senior, C. A., Stevens, B., Stouffer, R. J., and Taylor, K. E.: Overview of the Coupled Model Intercomparison Project Phase 6 (CMIP6) experimental design and organization, Geosci. Model Dev., 9, 1937-1958, https://doi.org/10.5194/gmd-9-1937-2016, 2016.

Forbes, R. M. and Ahlgrimm, M.: On the Representation of High-Latitude Boundary Layer Mixed-Phase Cloud in the ECMWF Global Model, Mon. Weather Rev., 142, 3425-3445, https://doi.org/10.1175/MWR-D-13-00325.1, 2014.

Forbes, R. M., Geer, A., Lonitz, K., and Ahlgrimm, M.: Reducing systematic errors in cold-air outbreaks, European Centre for Medium-Range Weather Forecasts, ECMWF Newsletter, No. 146, 17-22, https://doi.org/10.21957/s 41h7q71, 2016.

Frey, W. R. and Kay, J. E.: The influence of extratropical cloud phase and amount feedbacks on climate sensitivity, Clim. Dynam., 50, 3097-3116, https://doi.org/10.1007/s00382-017-37965,2018 .
Geleyn, J.-F. and Hollingsworth, A.: An economical analytical method for the computation of the interaction between scattering and line absorption of radiation, Beitr. Phys. Atmos., 52, 1-16, 1979.

Guo, Z., Wang, M., Qian, Y., Larson, V. E., Ghan, S., Ovchinnikov, M., Bogenschutz, P. A., Zhao, C., Lin, G., and Zhou, T.: A sensitivity analysis of cloud properties to CLUBB parameters in the single-column Community Atmosphere Model (SCAM5), J. Adv. Model. Earth Syst., 6, 829-858, https://doi.org/10.1002/2014MS000315, 2015.

Hahn, C. J. and Warren, S. G.: Extended edited synoptic cloud reports from ships and land stations over the globe, 1952-1996 (2009 update). NDP-026C, Carbon Dioxide Information Analysis Center, Oak Ridge National Laboratory, Oak Ridge, TN, 2009.

Heymsfield, A. J.: Precipitation Development in Stratiform Ice Clouds: A Microphysical and Dynamical Study, J. Atmos. Sci., 34, 367-381, https://doi.org/10.1175/15200469(1977)034<0367:PDISIC>2.0.CO;2, 1977.

Heymsfield, A. J. and Donner, L. J.: A Scheme for Parameterizing Ice-Cloud Water Content in General Circulation Models, J. Atmos. Sci., 47, 1865-1877, https://doi.org/10.1175/15200469(1990)047<1865:ASFPIC>2.0.CO;2, 1990.

Heymsfield, A. J. and Iaquinta, J.: Cirrus Crystal Terminal Velocities, J. Atmos. Sci., 57, 916-938, https://doi.org/10.1175/15200469(2000)057<0916:CCTV>2.0.CO;2, 2000.

Hoose, C., Kristjánsson, J. E., Iversen, T., Kirkevåg, A., Seland, Ø., and Gettelman, A.: Constraining cloud droplet number concentration in GCMs suppresses the aerosol indirect effect, Geophys. Res. Lett., 36, L12807, https://doi.org/10.1029/2009GL038568, 2009.

Hu, Y., Rodier, S., Xu, K. M., Sun, W., Huang, J., Lin, B., Zhai, P., and Josset, D.: Occurrence, liquid water content, and fraction of supercooled water clouds from combined CALIOP/IIR/MODIS measurements, J. Geophys. Res., 115, D00H34, https://doi.org/10.1029/2009JD012384, 2010.

Jakob, C.: The representation of cloud cover in Atmospheric General Circulation Models, thesis, Fakultat fur Physik der LudwigMaximilians-Universitat, European Centre for Medium-Range Weather Forecasts, submitted, 2000.

Jiang, J. H., Su, H., Zhai, C., Perun, V. S., Del Genio, A., Nazarenko, L. S., Donner, L. J., Horowitz, L., Seman, C., Cole, J., Gettelman, A., Ringer, M. A., Rotstayn, L., Jeffrey, S., Wu, T., Brient, F., Dufresne, J. L., Kawai, H., Koshiro, T., Watanabe, M., Lécuyer, T. S., Volodin, E. M., Iversen, T., Drange, H., Mesquita, M. D. S., Read, W. G., Waters, J. W., Tian, B., Teixeira, J., and Stephens, G. L.: Evaluation of cloud and water vapor simulations in CMIP5 climate models Using NASA "A-Train" satellite observations, J. Geophys. Res., 117, D14105, https://doi.org/10.1029/2011JD017237, 2012.

Jones, A., Roberts, D. L., Woodage, M. J., and Johnson, C. E.: Indirect sulphate aerosol forcing in a climate model with an interactive sulphur cycle, J. Geophys. Res., 106, 20293-20310, https://doi.org/10.1029/2000JD000089, 2001.

Kärcher, B. and Lohmann, U.: A Parameterization of cirrus cloud formation: Homogeneous freezing including effects of aerosol size, J. Geophys. Res., 107, 4698, https://doi.org/10.1029/2001JD001429, 2002. 
Kärcher, B. and Lohmann, U.: A parameterization of cirrus cloud formation: Heterogeneous freezing, J. Geophys. Res., 108, 4402, https://doi.org/10.1029/2002JD003220, 2003.

Kärcher, B., Hendricks, J., and Lohmann, U.: Physically based parameterization of cirrus cloud formation for use in global atmospheric models, J. Geophys. Res., 111, D01205, https://doi.org/10.1029/2005JD006219, 2006.

Kawai, H.: Improvement of a Cloud Ice Fall Scheme in GCM, CAS/JSC WGNE Research Activities in Atmospheric and Oceanic Modelling/WMO, 35, 4.11-4.12, 2005.

Kawai, H.: Improvement of a Stratocumulus Scheme for Midlatitude Marine Low Clouds, CAS/JSC WGNE Research Activities in Atmospheric and Oceanic Modelling/WMO, 43, 4.034.04, 2013.

Kawai, H. and Inoue, T.: A simple parameterization scheme for subtropical marine stratocumulus, SOLA, 2, 17-20, https://doi.org/10.2151/sola.2006-005, 2006.

Kawai, H., Yabu, S., Hagihara, Y., Koshiro, T., and Okamoto, H.: Characteristics of the cloud top heights of marine boundary layer clouds and the frequency of marine fog over mid-latitudes, J. Meteorol. Soc. Jpn., 93, 613-628, https://doi.org/10.2151/jmsj.2015-045, 2015a.

Kawai, H., Koshiro, T., Webb, M., Yukimoto, S., and Tanaka, T.: Cloud feedbacks in MRI-CGCM3, CAS/JSC WGNE Research Activities in Atmospheric and Oceanic Modelling/WMO, 45, 7.11-7.12, 2015b.

Kawai, H., Koshiro, T., and Webb, M. J.: Interpretation of factors controlling low cloud cover and low cloud feedback using a unified predictive index, J. Climate, 30, 9119-9131, https://doi.org/10.1175/JCLI-D-16-0825.1, 2017.

Kawai, H., Koshiro, T., Endo, H., and Arakawa, O.: Changes in marine fog over the North Pacific under different climates in CMIP5 multimodel simulations, J. Geophys. Res.-Atmos., 123, 1091110924, https://doi.org/10.1029/2018JD028899, 2018.

Kay, J. E., Wall, C., Yettella, V., Medeiros, B., Hannay, C., Caldwell, P., and Bitz, C.: Global climate impacts of fixing the Southern Ocean shortwave radiation bias in the Community Earth System Model (CESM), J. Climate, 29, 4617-4636, https://doi.org/10.1175/JCLI-D-15-0358.1, 2016.

Klein, S. A. and Hartmann, D. L.: The seasonal cycle of low stratiform clouds, J. Climate, 6, 1587-1606, https://doi.org/10.1175/15200442(1993)006<1587:TSCOLS>2.0.CO;2, 1993.

Koshiro, T., Shiotani, M., Kawai, H., and Yukimoto, S.: Evaluation of Relationships between Subtropical Marine Low Stratiform Cloudiness and Estimated Inversion Strength in CMIP5 Models Using the Satellite Simulator Package COSP, SOLA, 14, 25-32, https://doi.org/10.2151/sola.2018-005, 2018.

Kuo, H.-C. and Schubert, W. H.: Stability of cloud-topped boundary layers, Q. J. Roy. Meteor. Soc., 114, 887-916, https://doi.org/10.1002/qj.49711448204, 1988.

Larson, K., Hartmann, D. L., and Klein, S. A.: The Role of Clouds, Water Vapor, Circulation, and Boundary Layer Structure in the Sensitivity of the Tropical Climate, J. Climate, 12), 2359-2374, https://doi.org/10.1175/15200442(1999)012<2359:TROCWV>2.0.CO;2, 1999.

Lauer, A. and Hamilton, K.: Simulating Clouds with Global Climate Models: A Comparison of CMIP5 Results with
CMIP3 and Satellite Data, J. Climate, 26, 3823-3845, https://doi.org/10.1175/JCLI-D-12-00451.1, 2013.

Lauer, A., Hamilton, K., Wang, Y., Phillips, V. T. J., and Bennartz, R.: The Impact of Global Warming on Marine Boundary Layer Clouds over the Eastern Pacific - A Regional Model Study, J. Climate, 23, 5844-5863, https://doi.org/10.1175/2010JCLI3666.1, 2010.

Levkov, L., Rockel, B., Kapitza, H., and Raschke, E.: 3D mesoscale numerical studies of cirrus and stratus clouds by their time and space evolution, Beitr. Phys. Atmos., 65, 35-58, 1992.

Li, J. L. F., Waliser, D. E., Stephens, G., Lee, S., L'Ecuyer, T., Kato, S., Loeb, N., and Ma, H. Y.: Characterizing and understanding radiation budget biases in CMIP3/CMIP5 GCMs, contemporary GCM, and reanalysis, J. Geophys. Res.-Atmos., 118, 8166-8184, https://doi.org/10.1002/jgrd.50378, 2013.

Liu, X., Easter, R. C., Ghan, S. J., Zaveri, R., Rasch, P., Shi, X., Lamarque, J.-F., Gettelman, A., Morrison, H., Vitt, F., Conley, A., Park, S., Neale, R., Hannay, C., Ekman, A. M. L., Hess, P., Mahowald, N., Collins, W., Iacono, M. J., Bretherton, C. S., Flanner, M. G., and Mitchell, D.: Toward a minimal representation of aerosols in climate models: description and evaluation in the Community Atmosphere Model CAM5, Geosci. Model Dev., 5, 709-739, https://doi.org/10.5194/gmd-5-709-2012, 2012.

Lock, A. P.: Factors influencing cloud area at the capping inversion for shallow cumulus clouds, Q. J. Roy. Meteor. Soc., 135, 941952, https://doi.org/10.1002/qj.424, 2009.

Loeb, N. G., Wielicki, B. A., Doelling, D. R., Smith, G. L., Keyes, D. F., Kato, S., Manalo-Smith, N., and Wong, T.: Toward Optimal Closure of the Earth's Top-of-Atmosphere Radiation Budget, J. Climate, 22, 748-766, https://doi.org/10.1175/2008JCLI2637.1, 2009.

Lohmann, U.: Possible Aerosol Effects on Ice Clouds via Contact Nucleation, J. Atmos. Sci., 59, 647-656, https://doi.org/10.1175/15200469(2001)059<0647:PAEOIC>2.0.CO;2, 2002.

Lohmann, U. and Diehl, K.: Sensitivity Studies of the Importance of Dust Ice Nuclei for the Indirect Aerosol Effect on Stratiform Mixed-Phase Clouds, J. Atmos. Sci., 63, 968-982, https://doi.org/10.1175/JAS3662.1, 2006.

Lohmann, U., Stier, P., Hoose, C., Ferrachat, S., Kloster, S., Roeckner, E., and Zhang, J.: Cloud microphysics and aerosol indirect effects in the global climate model ECHAM5-HAM, Atmos. Chem. Phys., 7, 3425-3446, https://doi.org/10.5194/acp-7-34252007, 2007.

MacVean, M. K.: A Numerical Investigation of the Criterion for Cloud-Top Entrainment Instability, J. Atmos. Sci., 50, 2481-2495, https://doi.org/10.1175/15200469(1993)050<2481:ANIOTC>2.0.CO;2, 1993.

MacVean, M. K. and Mason, P. J.: Cloud-Top Entrainment Instability through Small-Scale Mixing and Its Parameterization in Numerical Models, J. Atmos. Sci., 47, 1012-1030, https://doi.org/10.1175/15200469(1990)047<1012:CTEITS>2.0.CO;2, 1990.

Manton, M. J. and Cotton, W. R.: Formulation of approximate equations for modeling moist deep convection on the mesoscale, Atmospheric Science Paper, No. 266, Colorado State University, 1977.

Mauritsen, T., Stevens, B., Roeckner, E., Crueger, T., Esch, M., Giorgetta, M., Haak, H., Jungclaus, J., Klocke, 
D., Matei, D., Mikolajewicz, U., Notz, D., Pincus, R., Schmidt, H., and Tomassini, L.: Tuning the climate of a global model, J. Adv. Model. Earth Syst., 4, M00A01, https://doi.org/10.1029/2012MS000154, 2012.

McCoy, D. T., Hartmann, D. L., Zelinka, M. D., Ceppi, P., and Grosvenor, D. P.: Mixed-phase cloud physics and Southern Ocean cloud feedback in climate models, J. Geophys. Res.-Atmos., 120, 9539-9554, https://doi.org/10.1002/2015JD023603, 2015.

McFarquhar, G. M. and Heymsfield, A. J.: Parameterization of Tropical Cirrus Ice Crystal Size Distributions and Implications for Radiative Transfer: Results from CEPEX, J. Atmos. Sci., 54, 2187-2200, https://doi.org/10.1175/15200469(1997)054<2187:POTCIC>2.0.CO;2, 1997.

Medeiros, B., Stevens, B., Held, I. M., Zhao, M., Williamson, D. L., Olson, J. G., and Bretherton, C. S.: Aquaplanets, Climate Sensitivity, and Low Clouds, J. Climate, 21, 4974-4991, https://doi.org/10.1175/2008JCLI1995.1, 2008.

Meyers, M. P., DeMott, P. J., and Cotton, W. R.: New Primary Ice-Nucleation Parameterizations in an Explicit Cloud Model, J. Appl. Meteorol., 31, 708-721, https://doi.org/10.1175/15200450(1992)031<0708:NPINPI>2.0.CO;2, 1992.

Miller, R. L.: Tropical Thermostats and Low Cloud Cover, J. Climate, 10, 409-440, https://doi.org/10.1175/15200442(1997)010<0409:TTALCC>2.0.CO;2, 1997.

Morrison, H. and Gettelman, A.: A New Two-Moment Bulk Stratiform Cloud Microphysics Scheme in the Community Atmosphere Model, Version 3 (CAM3). Part I: Description and Numerical Tests, J. Climate, 21, 3642-3659, https://doi.org/10.1175/2008JCLI2105.1, 2008.

Murakami, M.: Numerical Modeling of Dynamical and Microphysical Evolution of an Isolated Convective Cloud - The 19 July 1981 CCOPE cloud, J. Meteor. Soc. Jpn., 68, 107-128, https://doi.org/10.2151/jmsj1965.68.2_107, 1990.

Nagasawa, R.: The Problem of Cloud Overlap in the Radiation Process of JMA's Global NWP Model, CAS/JSC WGNE Research Activities in Atmospheric and Oceanic Modelling/WMO, 42, 0415-0416, 2012.

Nam, C., Bony, S., Dufresne, J. L., and Chepfer, H.: The 'too few, too bright' tropical low-cloud problem in CMIP5 models, Geophys. Res. Lett., 39, L21801, https://doi.org/10.1029/2012GL053421, 2012.

Neubauer, D., Lohmann, U., Hoose, C., and Frontoso, M. G.: Impact of the representation of marine stratocumulus clouds on the anthropogenic aerosol effect, Atmos. Chem. Phys., 14, 1199712022, https://doi.org/10.5194/acp-14-11997-2014, 2014.

Nuijens, L., Medeiros, B., Sandu, I., and Ahlgrimm, M.: The behavior of trade-wind cloudiness in observations and models: The major cloud components and their variability, J. Adv. Model. Earth Syst., 7, 600-616, https://doi.org/10.1002/2014MS000390, 2015.

Pincus, R., Platnick, S., Ackerman, S. A., Hemler, R. S., and Patrick Hofmann, R. J.: Reconciling simulated and observed views of clouds: MODIS, ISCCP, and the limits of instrument simulators, J. Climate, 25, 4699-4720, https://doi.org/10.1175/JCLI-D-11$00267.1,2012$.

Qu, X., Hall, A., Klein, S. A., and Caldwell, P. M.: On the spread of changes in marine low cloud cover in climate model sim- ulations of the 21st century, Clim. Dynam., 42, 2603-2626, https://doi.org/10.1007/s00382-013-1945-z, 2014.

Rahn, D. A. and Garreaud, R.: Marine boundary layer over the subtropical southeast Pacific during VOCALS-REx - Part 1: Mean structure and diurnal cycle, Atmos. Chem. Phys., 10, 4491-4506, https://doi.org/10.5194/acp-10-4491-2010, 2010.

Randall, D. A.: Conditional Instability of the First Kind Upside-Down, J. Atmos. Sci. 37, 125-130, $\quad$ https://doi.org/10.1175/15200469(1980)037<0125:CIOTFK>2.0.CO;2, 1980.

Rossow, W. B. and Schiffer, R. A.: Advances in Understandig Clouds from ISCCP, B. Am. Meteorol Soc., $\quad 80, \quad 2261-2287, \quad$ https://doi.org/10.1175/15200477(1999)080<2261:AIUCFI>2.0.CO;2, 1999.

Rotstayn, L. D.: A physically based scheme for the treatment of stratiform clouds and precipitation in large-scale models. I: Description and evaluation of the microphysical processes, Q. J. Roy. Meteor. Soc., 123, 1227-1282, https://doi.org/10.1002/qj.49712354106, 1997.

Rotstayn, L. D.: On the "tuning" of autoconversion parameterizations in climate models, J. Geophys. Res., 105, 15495-15507, https://doi.org/10.1029/2000JD900129, 2000.

Rutledge, S. A. and Hobbs, P.: The Mesoscale and Microscale Structure and Organization of Clouds and Precipitation in Midlatitude Cyclones. VIII: A Model for the "Seeder-Feeder" Process in Warm-Frontal Rainbands, J. Atmos. Sci., 40, 1185-1206, https://doi.org/10.1175/15200469(1983)040<1185:TMAMSA>2.0.CO;2, 1983.

Seinfeld, J. H., and Pandis, S. N.: Atmospheric Chemistry and Physics: From Air Pollution to Climate Change 2nd ed, John Wiley \& Sons, New York, USA, 1203, 2006.

Siebesma, A. P., Jakob, C., Lenderink, G., Neggers, R. A. J., Teixeira, J., van Meijgaard, E., Calvo, J., Chlond, A., Grenier, H., Jones, C., Köhler, M., Kitagawa, H., Marquet, P., Lock, A. P., Müller, F., Olmeda, D. C., and Severijns, C.: Cloud representation in general-circulation models over the northern Pacific Ocean: A EUROCS intercomparison study, Q. J. Roy. Meteor. Soc., 130, 3245-3267, https://doi.org/10.1256/qj.03.146, 2004.

Slingo, J. M.: A cloud parametrization scheme derived from GATE data for use with a numerical model, Q. J. Roy. Meteor. Soc., 106, 747-770, https://doi.org/10.1002/qj.49710645008, 1980.

Slingo, J. M.: The Development and Verification of A Cloud Prediction Scheme For the Ecmwf Model, Q. J. Roy. Meteor. Soc. 113, 899-927, https://doi.org/10.1002/qj.49711347710, 1987.

Smith, R. N. B.: A scheme for predicting layer clouds and their water content in a general circulation model, Q. J. Roy. Meteor. Soc., 116, 435-460, https://doi.org/10.1002/qj.49711649210, 1990.

Soden, B. J. and Held, I. M.: An Assessment of Climate Feedbacks in Coupled Ocean - Atmosphere Models, J. Climate, 19, 3354 3360, https://doi.org/10.1175/JCLI9028.1, 2006.

Soden, B. J., Held, I. M., Colman, R. C., Shell, K. M., Kiehl, J. T., and Shields, C. A.: Quantifying climate feedbacks using radiative kernels, J. Climate, 21, 3504-3520, https://doi.org/10.1175/2007JCLI2110.1, 2008.

Su, H., Jiang, J. H., Zhai, C., Perun, V. S., Shen, J. T., Del Genio, A., Nazarenko, L. S., Donner, L. J., Horowitz, L., Seman, C., Morcrette, C., Petch, J., Ringer, M., Cole, J., Von Salzen, K., Mesquita, M. D. S., Iversen, T., Kristjansson, J. E., Gettel- 
man, A., Rotstayn, L., Jeffrey, S., Dufresne, J. L., Watanabe, M., Kawai, H., Koshiro, T., Wu, T., Volodin, E. M., L'Ecuyer, T., Teixeira, J., and Stephens, G. L.: Diagnosis of regime-dependent cloud simulation errors in CMIP5 models using "a-Train" satellite observations and reanalysis data, J. Geophys. Res.-Atmos., 118, 2762-2780, https://doi.org/10.1029/2012JD018575, 2013.

Suzuki, K., Stephens, G., Bodas-Salcedo, A., Wang, M., Golaz, J.C., Yokohata, T., and Koshiro, T.: Evaluation of the Warm Rain Formation Process in Global Models with Satellite Observations, J. Atmos. Sci., 72, 3996-4014, https://doi.org/10.1175/JAS-D14-0265.1, 2015.

Takemura, T., Nozawa, T., Emori, S., Nakajima, T. Y., and Nakajima, T.: Simulation of climate response to aerosol direct and indirect effects with aerosol transport-radiation model, J. Geophys. Res., 110, D02202, https://doi.org/10.1029/2004JD005029, 2005.

Tan, I. and Storelvmo, T.: Sensitivity Study on the Influence of Cloud Microphysical Parameters on Mixed-Phase Cloud Thermodynamic Phase Partitioning in CAM5, J. Atmos. Sci., 73, 709-728, https://doi.org/10.1175/JAS-D-15-0152.1, 2016.

Tan, I., Storelvmo, T., and Zelinka, M. D.: Observational constraints on mixed-phase clouds imply higher climate sensitivity, Science, 352, 224-227, https://doi.org/10.1126/science.aad5300, 2016.

Tanaka, T. Y., Orito, K., Sekiyama, T. T., Shibata, K., Chiba, M., and Tanaka, H.: MASINGAR, a global tropospheric aerosol chemical transport model coupled with MRI/JMA98 GCM: Model description, Pap. Meteorol. Geophys., 53, 119-138, https://doi.org/10.2467/mripapers.53.119, 2003.

Taylor, K. E.: Summarizing multiple aspects of model performance in a single diagram, J. Geophys. Res., 106, 7183-7192, https://doi.org/10.1029/2000JD900719, 2001.

Taylor, K. E., Stouffer, R. J., and Meehl, G. A.: An Overview of CMIP5 and the Experiment Design, B. Am. Meteorol. Soc., 93, 485-498, https://doi.org/10.1175/BAMS-D-11-00094.1, 2012.

Teixeira, J.: The impact of increased boundary layer vertical resolution on the ECMWF forecast system, European Centre for Medium-Range Weather Forecasts, ECMWF technical memorandum, 268, 1-55, 1999.

Tiedtke, M.: Representation of Clouds in Large-Scale Models, Mon. Weather Rev., 121, 3040-3061, 1993.

Trenberth, K. E. and Fasullo, J. T.: Simulation of present-day and twenty-first-century energy budgets of the southern oceans, J. Climate., 23, 440-454, https://doi.org/10.1175/2009JCLI3152.1, 2010.

Tsushima, Y., Emori, S., Ogura, T., Kimoto, M., Webb, M. J., Williams, K. D., Ringer, M. A., Soden, B. J., Li, B., and Andronova, N.: Importance of the mixed-phase cloud distribution in the control climate for assessing the response of clouds to carbon dioxide increase: a multi-model study, Clim. Dynam., 27, 113-126, https://doi.org/10.1007/s00382-006-0127-7, 2006.

Tsushima, Y., Ringer, M. A., Webb, M. J., and Williams, K. D.: Quantitative evaluation of the seasonal variations in climate model cloud regimes, Clim. Dynam., 41, 2679-2696, https://doi.org/10.1007/s00382-012-1609-4, 2013.

Tsushima, Y., Ringer, M. A., Koshiro, T., Kawai, H., Roehrig, R., Cole, J., Watanabe, M., Yokohata, T., Bodas-Salcedo, A., Williams, K. D., and Webb, M. J.: Robustness, uncertainties, and emergent constraints in the radiative responses of stratocu- mulus cloud regimes to future warming, Clim. Dynam., 46, https://doi.org/10.1007/s00382-015-2750-7, 2016.

Uppala, S. M., Kållberg, P. W., Simmons, A. J., Andrae, U., Bechtold, V. D. C., Fiorino, M., Gibson, J. K., Haseler, J., Hernandez, A., Kelly, G. A., Li, X., Onogi, K., Saarinen, S., Sokka, N., Allan, R. P., Andersson, E., Arpe, K., Balmaseda, M. A., Beljaars, A. C. M., Berg, L. Van De, Bidlot, J., Bormann, N., Caires, S., Chevallier, F., Dethof, A., Dragosavac, M., Fisher, M., Fuentes, M., Hagemann, S., Hólm, E., Hoskins, B. J., Isaksen, L., Janssen, P. A. E. M., Jenne, R., Mcnally, A. P., Mahfouf, J.-F., Morcrette, J.-J., Rayner, N. A., Saunders, R. W., Simon, P., Sterl, A., Trenberth, K. E., Untch, A., Vasiljevic, D., Viterbo, P., and Woollen, J.: The ERA-40 re-analysis, Q. J. Roy. Meteor. Soc., 131, 29613012, https://doi.org/10.1256/qj.04.176, 2005.

Wang, Y., Xu, H. and Xie, S.-P.: Regional Model Simulations of Marine Boundary Layer Clouds over the Southeast Pacific off South America. Part II: Sensitivity Experiments, Mon. Weather Rev., 132, 2650-2668, https://doi.org/10.1175/MWR2812.1, 2004.

Webb, M. J., Lambert, F. H., and Gregory, J. M.: Origins of differences in climate sensitivity, forcing and feedback in climate models, Clim. Dynam., 40, 677-707, https://doi.org/10.1007/s00382012-1336-x, 2013.

Webb, M. J., Andrews, T., Bodas-Salcedo, A., Bony, S., Bretherton, C. S., Chadwick, R., Chepfer, H., Douville, H., Good, P., Kay, J. E., Klein, S. A., Marchand, R., Medeiros, B., Siebesma, A. P., Skinner, C. B., Stevens, B., Tselioudis, G., Tsushima, Y., and Watanabe, M.: The Cloud Feedback Model Intercomparison Project (CFMIP) contribution to CMIP6, Geosci. Model Dev., 10, 359-384, https://doi.org/10.5194/gmd-10-359-2017, 2017.

Williams, K. D., Ringer, M. A., Senior, C. A., Webb, M. J., McAvaney, B. J., Andronova, N., Bony, S., Dufresne, J. L., Emori, S., Gudgel, R., Knutson, T., Li, B., Lo, K., Musat, I., Wegner, J., Slingo, A., and Mitchell, J. F. B.: Evaluation of a component of the cloud response to climate change in an intercomparison of climate models, Clim. Dynam., 26, 145-165, https://doi.org/10.1007/s00382-005-0067-7, 2006.

Wilson, D. R., Smith, R. N. B., Gregory, D., Wilson, C. A., Bushell, A. C., and Cusack, S.: The large-scale cloud scheme and saturated specific humidity, Unified Model documentation paper, 29, Met Office, Exeter, UK, 2007.

Wilson, D. R., Bushell, A. C., Kerr-Munslow, A. M., Price, J. D., Morcrette, C. J., and Bodas-Salcedo, A.: PC2: A prognostic cloud fraction and condensation scheme. II: Climate model simulations, Q. J. Roy. Meteor. Soc., 134, 2109-2125, https://doi.org/10.1002/qj.332, 2008.

Winker, D. M., Vaughan, M. A., Omar, A., Hu, Y., Powell, K. A., Liu, Z., Hunt, W. H., and Young, S. A.: Overview of the CALIPSO Mission and CALIOP Data Processing Algorithms, J. Atmos. Ocean. Tech., 26, 2310-2323, https://doi.org/10.1175/2009JTECHA1281.1, 2009.

Wood, R.: Stratocumulus Clouds, Mon. Weather Rev., 140, 2373 2423, https://doi.org/10.1175/MWR-D-11-00121.1, 2012.

Wood, R. and Bretherton, C. S.: On the relationship between stratiform low cloud cover and lower-tropospheric stability, J. Climate, 19, 6425-6432, https://doi.org/10.1175/JCLI3988.1, 2006.

Yamaguchi, T. and Randall, D. A.: Large-Eddy Simulation of Evaporatively Driven Entrainment in Cloud- 
Topped Mixed Layers, J. Atmos. Sci., 65, 1481-1504, https://doi.org/10.1175/2007JAS2438.1, 2008.

Yukimoto, S., Yoshimura, H., Hosaka, M., Sakami, T., Tsujino, H., Hirabara, M., Tanaka, T. Y., Deushi, M., Obata, A., Nakano, H., Adachi, Y., Shindo, E., Yabu, S., Ose, T., and Kitoh, A.: Meteorological Research Institute Earth System Model Version 1 (MRIESM1) - Model Description, Tech. Rep. of MRI, 64, 83 pp., available at: http://www.mri-jma.go.jp/Publish/Technical/index_ en.html (last access: 4 July 2019), 2011.

Yukimoto, S., Adachi, Y., Hosaka, M., Sakami, T., Yoshimura, H., Hirabara, M., Tanaka, T. Y., Shindo, E., Tsujino, H., Deushi, M., Mizuta, R., Yabu, S., Obata, A., Nakano, H., Koshiro, T., Ose, T., and Kitoh, A.: A new global climate model of the Meteorological Research Institute: MRI-CGCM3 -Model Description and Basic Performance, J. Meteorol. Soc. Jpn., 90A, 23-64, https://doi.org/10.2151/jmsj.2012-A02, 2012.
Yukimoto, S., Kawai, H., Koshiro, T., Oshima, N., Yoshida, K., Urakawa, S., Tsujino, H., Deushi, M., Tanaka, T., Hosaka, M., Yabu, S., Yoshimura, H., Shindo, E., Mizuta, R., Obata, A., Adachi, Y. and Ishii, M.: The Meteorological Research Institute Earth System Model version 2.0, MRI-ESM2.0: Description and basic evaluation of the physical component, J. Meteor. Soc. Jpn., 97, https://doi.org/10.2151/jmsj.2019-051, in press, 2019.

Zhang, Y., Xie, S., Covey, C., Lucas, D. D., Gleckler, P., Klein, S. A., Tannahill, J., Doutriaux, C., and Klein, R.: Regional assessment of the parameter-dependent performance of CAM4 in simulating tropical clouds, Geophys. Res. Lett., 39, L14708, https://doi.org/10.1029/2012GL052184, 2012.

Zurovac-Jevtić, D. and Zhang, G. J.: Development and Test of a Cirrus Parameterization Scheme Using NCAR CCM3, J. Atmos. Sci., 60, 1325-1344, https://doi.org/10.1175/15200469(2003)060<1325:DATOAC >2.0.CO;2, 2003. 